\title{
Upstream Volatility in the Supply Chain: The Machine Tool Industry as a Case Study ${ }^{1}$
}

\author{
E.G. Anderson Jr. \\ C.H. Fine \\ G.J. Gilboy \\ G.G. Parker
}

MIT Sloan School of Management, Cambridge MA

Working Draft, May 1995. Please do not cite without authors' permission.

\begin{abstract}
Cyclicality is a well known and accepted fact of life in market driven economies. Less well known or understood, however, is the phenomenon of amplification as one looks "upstream" in the industrial supply chain. This paper discusses and explains the amplification phenomenon and its implications through the lens of one "upstream" industry that is notorious for the intensity of the business cycles it faces: the machine tool industry. Using a sparse simulation model, we have replicated much of the behavior seen in the industrial world in which machine tool companies operate. This model has allowed us to test and confirm many of our hypotheses. Two results stand out. Even though machine tool builders can do little to reduce their production volatility through choice of forecast rule, a longer view of the future leads companies to retain more of their skilled workforce. This is often cited as one of the advantages that European and Japanese companies have enjoyed: lower skilled employee turnover. The second, and most important result is that machine tool customers can do a great deal to reduce the volatility for machine tool builders through their choice of order forecast rule. Companies which use a longer horizon over which to forecast orders tend to impose less of their own volatility upon their supply base.
\end{abstract}

\footnotetext{
${ }_{1}^{1}$ Financial support for this project from within MIT--Leaders for Manufacturing, the International Motor Vehicle Program, the Industrial Performance Center, the International Center for Research on the Management of Technology, and the Japan Program--as well as from Chrysler, Intel, Sematech, and Texas Instruments, is gratefully acknowledged.
} 


\section{Table of Contents}

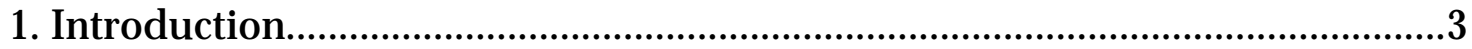

2. The Critical Role of the Machine Tool Industry in the Economy.................6

3. Comparative Data and Case Studies................................................................

Figure 3.1: U.S. Machine Tool Volatility........................................

Figure 3.2 Supply Chain Volatility Increases Upstream...............9

Reducing Volatility: The Case of DCT and PICO......................................

Forward Integration: The Case of Bihler America....................................10

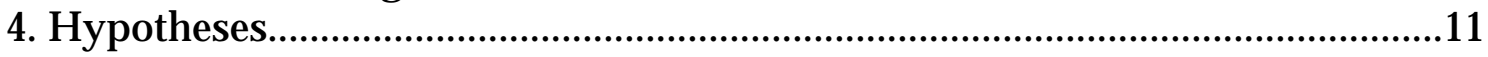

5. Methodology \& Model Description.................................................................15

Model Overview .......................................................................................16

Constants Used in Base Model...............................................................18

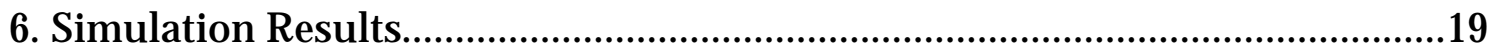

Comparison of simulated with actual data..............................................19

Response of the machine supplier to a step-input...................................19

Comparison with the Beer-Game Effect...................................................20

Hypothesis 2: Average Machine-Tool Maker Employment....................20

Hypothesis 3: Average Machine-Tool Maker Employee Exp.................21

Hypothesis 4: Cost reduction.........................................................................21

Hypothesis 5: Reducing Machine Production Lead-Time........................22

Hypothesis 6: Widget-Maker Policies vs. Machine-Maker.....................22

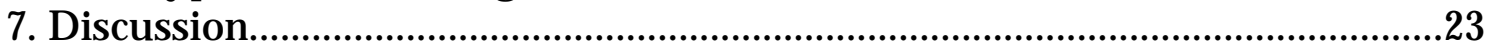

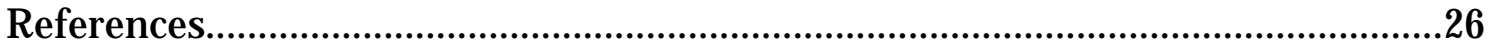

Appendix A. Model Equation Descriptions......................................................2.

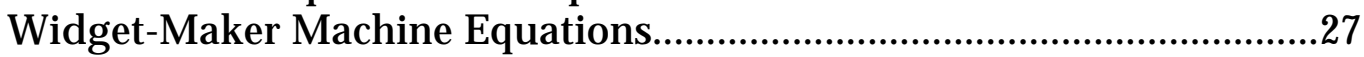

Machine Maker Production Equations.......................................................27

Machine Maker Forecasting Equations.........................................................28

Machine Maker Hiring and Attrition Equations......................................22

Machine Maker Employee Termination Equations....................................30

Machine Maker Employment Level Equations...........................................30

Widget Production System.............................................................................31 


\section{Introduction}

Cyclicality is a well known and accepted fact of life in market driven economies. Less well known or understood, however, is the phenomenon of amplification as one looks "upstream" in the industrial capital equipment supply chain. This paper discusses and explains the amplification phenomenon (related, but not identical to the "bullwhip" or "beer-game" phenomena ${ }^{2}$ ) and its implications through the lens of one "upstream" industry that is notorious for the intensity of the business cycles it faces: the machine tool industry. ${ }^{3}$ It should be noted, however, that the volatility faced by the machine tool industry is also faced by many other, less well know, capital equipment manufacturers.

In some ways, the machine tool industry is the knot at the end of the whip of the economy. The industry displays many of the same cyclical characteristics of the economy in general, but like the end of the whip, the distance traveled is greater, the speed is higher, and the effects more pronounced. Just as manufacturing slowdowns often presage economic downturns, the machine tool industry leads the manufacturing sector in periods of contraction. But whereas the manufacturing sector often leads the economy into recovery, machine tool production lags during the beginning of recoveries. The normal cycle of the economy is thus compressed for the machine tool industry: peaks are shorter, and troughs are longer. Almost the first thing manufacturers do when they believe a contraction is imminent (that is, before a recession is "official") is halt the purchase of capital goods. And manufacturers want to be certain that a recovery is underway before they resume purchase of capital goods, so they are much more likely to wait until the recovery is solidly established, before they order capital equipment again.

In the past, the U.S. machine tool industry has attempted to cut a way out of this volatility box by shifting emphasis to export markets when domestic markets were depressed. Of course, if there are simultaneous recessions at home and abroad in key machine tool markets, then the

\footnotetext{
${ }^{2}$ See, J. D. Sterman, "Modeling Managerial Behavior: Misperceptions of Feedback in a Dynamic Decision Making Experiment," Management Science, (35) 3: 321-339, March, 1989, and H. Lee, P. Padmanabhan, and S. Whang, "Information Distortion in a Supply Chain: The Bullwhip Effect," Stanford University Working Paper, 1994.

${ }^{3}$ Max Holland, When the Machine Stopped, Harvard Business School Press, 1989.
} 
cyclicality problem for the machine tool industry is at its worst. This is what happened in 1992. World machine tool production declined by $19 \%$, the worst recorded year for the industry since 1963.

The traditional strategy of shifting to export markets during downturns at home is also hampered by the intensity of competition in those markets. Japanese, German, Swiss, and Italian firms also seek to strengthen their export sales during downturns at home, and companies from those countries also compete intensely in their own home markets, which are also key machine tool markets.

Another traditional strategy for American machine tool builders was to build up a large stock of backlogged orders to tide the company over during downturns. Backlogs meant that tool builders didn't get caught with excess manufacturing capacity of their own, when orders dried up. This strategy backfired in the 1970s and 1980s, by inviting foreign competitors to challenge American machine tool companies with not only new technology and competitive prices, but also speed of delivery as competitive advantages. By 1986 the American industry was reeling; with many small, weak companies, customers who did not value manufacturing (and equipment) as highly as their own foreign competitors, and foreign competition that now ate up a significant portion of the "up" cycles when they came.

The volatility problem is one reason that the machine tool industry seems constantly in a state of siege. Rarely do machine tool executives get a chance rest on their laurels, while business leaders, consultants, academics and government leaders all seem to worry constantly over the fate of the industry. If the industry is a strategic asset - an essential building block for prosperity and security - what can be done to understand the sources of its volatility and to test policies which might strengthen it?

This last question about what can be done to strengthen the machine tool industry is the central issue we address here. To inform our analysis, we offer a sparse model of the machine tool industry which uses the tool of system dynamics to explain the exceptional volatility seen in the industry and to test various strategies which customers and suppliers might pursue to improve the functioning of the machine tool industry. In developing our understanding of these phenomena, we have benefited from the work of Lee, Padmanabhan, and Whang who develop a model to show that the "bullwhip" effect will be absent only if all of the following conditions hold: 
(1) demand is stationary with its distribution known to all members, (2) all orders are delivered on time in requested quantity, (3) inventory levels are monitored every period and replenishing orders are issued immediately, and (4) the price at each node remains the same across all periods. We have also benefited from the work of Robert Kallenberg who has explained machine tool volatility with an alternate system dynamics model formulation.

Section 2 will offer justification for our belief in the criticality of the machine tool industry to the maintenance and building of world-class manufacturing.

In section 3, we review cases from our field studies over the past three years which serve to motivate the model we have developed. We also review some of the economic data which demonstrates the volatility with which we are concerned.

Section 4 describes the hypotheses we have tested with the model so far. These hypotheses consider the impact of "external" inputs such as overall economic activity, and the impact of actions more endogenous to the system modeled: the order forecast policies of both customers and machine tool suppliers.

In section 5, we discuss the methodology of this study, including the structure of the model. The method of system dynamics is employed to deal with the non-linear nature of the machine tool industry, and the large delays and feedbacks which cause researchers using linear models to have difficulty describing this environment.

In section 6, each of the hypotheses is tested and results are reported. In general, the model supports the hypotheses under consideration.

Finally, section 7 considers some of the broader implications of this work, and potential areas for future investigation. In particular, we hope to broaden our field research activities in the U.S., Japan and Germany, in order to more fully explore the development of regional institutions and individual business strategies that nurture cooperation among machine tool builders and their customers, and to test the effectiveness of those arrangements. 


\section{The Critical Role of the Machine Tool Industry in the Economy}

Machine tools are non-hand-held, powered machines that cut or form metal. Many observers and industry leaders view the machine tool industry as a strategically important one for the overall prosperity and security of the United States. ${ }^{4}$ Because they are the direct implements that turn raw materials into intermediate products, machine tools are a critical link in the industrial production chain. They are also the means by which we produce, and reproduce, the implements of manufacturing. In effect, the capabilities of machine tools determine to a large degree the quality and cost of a nation's manufactured goods. Precision, flexibility, and reliability of machine tools greatly affect the cost of manufacturing, the ability to respond to changes in demand, and the appeal of finished products to the consumer, both in terms of price and quality. Machine tools embody a large part of the total knowledge and capabilities we have for manufacturing.

But why is it important to have a world class domestic machine tool industry? The argument presented below is cast in terms of American interests, but applies with equal force to any nation that desires to attain global industrial and political leadership. There are three main points. First, a poorly performing industry loses out directly in sales, profits and highpaying jobs for Americans. ${ }^{5}$ Second, the industry loses opportunities to improve and innovate, because its reduced resources are less able to sustain research and development, and the search for new markets and applications - these opportunity costs not only cut off avenues for growth, but they help to ensure a less dynamic manufacturing sector, and thus a less dynamic economy. And third, a healthy domestic industry is important because it ensures that American manufacturers have timely access to the latest manufacturing equipment. This last point bears some further explanation.

In classical trade theory, machine tools would be seen as any other commodity input to production, sold in all accessible markets simultaneously

\footnotetext{
4See, for example, MIT Commission on Industrial Productivity, "The U.S. Machine Tool Industry and Its Foreign Competitors," in the Working Papers of the MIT Commission on Industrial Productivity, MIT Press, 1989; Association for Manufacturing Technology, "Vision 2000: A Winning Strategy For American Industry," AMT, 1990; U.S. Department of Defense, Critical Industries Planning, 1990; American Machinist, March 1993, pp. 32-37.

${ }^{5}$ See Krugman, Peddling Prosperity, 1994, for an alternate view that manufacturing does not inherently have more value-added jobs than other sectors of the economy.
} 
to anyone who can afford to buy them. In reality, American manufacturers have encountered difficulty in getting the latest technology and machines from foreign suppliers as soon as their direct foreign competitors do. There is no conspiracy involved, no machinations of foreign state-industry "Incs." that cause this difficulty. Normal business practices of filling local markets first, and of satisfying long term, close-at-hand customers account for the problem. Proximity to the latest developments may also help foreign users get a jump on learning about new manufacturing methods and tools, and how best to employ them, thus stealing a march on the learning curve associated with the application and operation of these complex machines. ${ }^{6}$ Proximity may also affect access to service and support for equipment. A General Motors representative summed it up this way:

"If you buy the very best from Japan, it has already been in Toyota Motors for two years, and if you buy from West Germany, it has already been with BMW for a year and a half."7

A natural objection to this line of argument is that a "transplant" maker of machine tools may be no different than a "domestic" company in its ability to provide domestic users with the best products and service. It is probably true that a well-run, well-heeled transplant may address some of these problems. But unless the transplant is a nearly autonomous operation, it must still refer important decisions to its home offices, and may stand second in line for new goods and technology. And if the subsidiary is a nearly autonomous operation, there is little reason to expect that it will have access to the latest technology and products, and service people, from the home operation. Some observers agree that transnational companies seem to have a "center of gravity" in one home market or another, and further, that for some (Japanese companies in particular) their purchasing policies, which favor "home" supplier, change only slowly over time. This may cause irreplaceable losses to domestic suppliers before the change comes. ${ }^{8}$ In short, a

\footnotetext{
${ }^{6}$ Sabel et al, “Collaborative Manufacturing," IMVP Working Paper, 1989; Paul Krugman, Geography and Trade, 1992.

${ }^{7}$ Quote in American Machinist, January 1986, as quoted in MIT Commission on Industrial Productivity, "The U.S. Machine Tool Industry and Its Foreign Competitors," in the Working Papers of the MIT Commission on Industrial Productivity, MIT Press, 1989, pp. 3.

${ }^{8}$ Krugman and Graham, Foreign Direct investment in the United States, 1992; see also OTA, Multinationals and the National Interest: Playing by Different Rules, 1993.
} 
transplant is better than arms-length importers, but does not offer many of the benefits of strong domestic companies.

Thus, a world class domestic machine tool industry is important to the overall health of the domestic economy. If American companies fall behind in machine tools, the equipment and products they manufacture may become inferior to their competitors'. If American manufacturers are to be assured of access to the latest and best machine tools, and Americans assured of a world class economy, the U.S. must have a world class machine tool industry.

\section{Comparative Data and Case Studies}

When we say that machine tool companies must function within an exceptionally volatile environment, what exactly do we mean? The following figure may help to explain:

Figure 3.1: U.S. Machine Tool Order Volatility, Year-to-Year \% Change

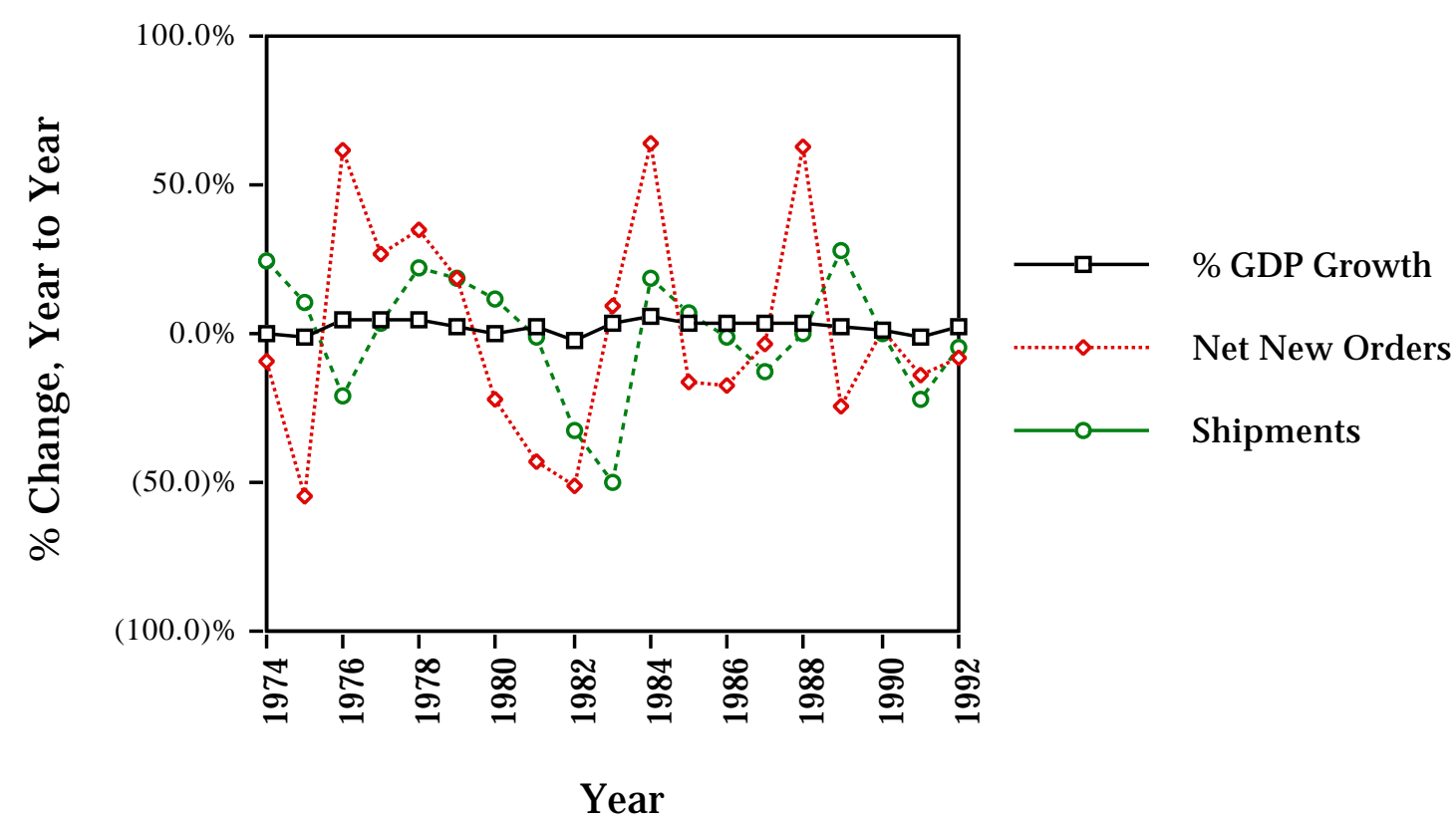

Data Source: Statistical Abstract of the United States

The Economic Handbook of the Machine Tool Industry, Association for Manufacturing Technology, 1993. 
In this figure, it can be seen that gross domestic product (GDP) generally changes only $+/-2$ or $3 \%$ in any given year. By contrast, orders and shipments of machine tools can change by more than $50 \%$ from one year to another. The methodology section of this paper will describe the dynamics which lead to such large swings. For now, consider the following picture of a supply chain. At each stage, the variability of the industry's output increases as the customer base for an industry's products narrows and the logic of deferring the purchase of long lived assets during downturns has its impact.

Figure 3.2 Supply Chain Volatility Increases Upstream

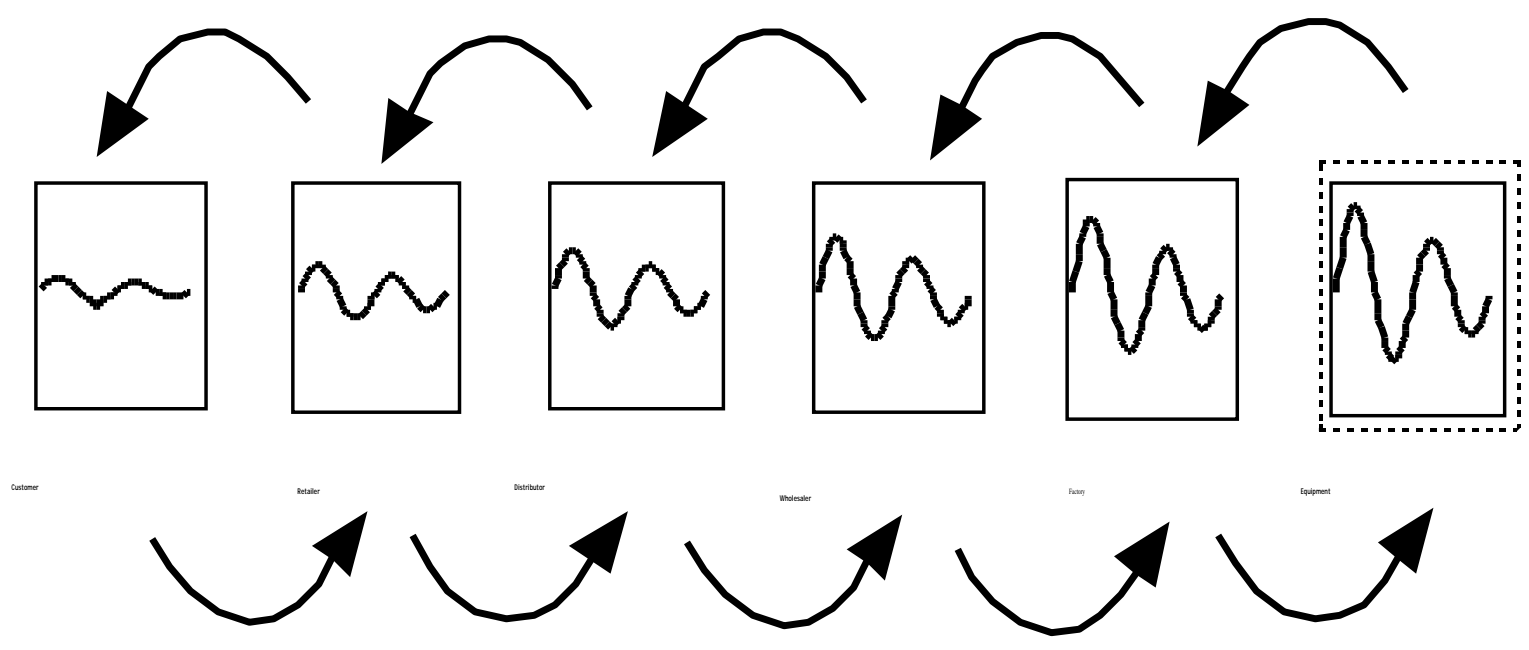

In section 5, we propose a model which explains the amplification of the business cycle the further upstream a business operates. Firms have many options to consider in attempting to deal with this volatility. The following cases describe some of these strategies.

\section{Reducing Volatility: The Case of DCT and PICO}

In the U.S. automobile industry, there has been substantial consolidation in the body-assembly tool making segment of the machine tool industry over the past decade. While not strictly a machine tool, an automobile body assembly system is a long lived capital asset which is sold in a market with dynamics similar to the machine tool industry. Two suppliers 
of automobile body manufacturing systems, Progressive Tool, Inc. (PICO) and Detroit Center Tool (DCT) have grown spectacularly in this period of consolidation. These companies have adapted to the reality that U.S. automobile assemblers wish to deal with larger, more competent suppliers than they dealt with in the past. Consequently, both of these firms have become "full service" suppliers. This means that the firms can supply resources from engineering teams to interact with customers in executing concurrent engineering projects to training teams which teach operators to use and maintain the equipment. These are dramatic changes from the industry's "drop it and leave it" history.

To offset the increase in fixed expenses represented by the addition of more engineering capability, both DCT and PICO have attempted to reduce their volatility through securing long term agreements to supply certain types of manufacturing systems to Ford and Chrysler. To the extent that the customers of the tool builders are willing to extend contracts throughout the business cycle, one expects that the volatility experienced by the upstream firms would be reduced. The real test will be to see what the order policies of the automobile assemblers are when they enter the next downturn.

An alternate response to managing the customer/supplier relationship is to change the environment is which the firm operates. Another machine tool builder has chosen to switch environments in response to the uniquely transient nature of selling manufacturing systems.

\section{Forward Integration: The Case of Bihler America}

Bihler Company, USA, is a small machine tool maker located in Western New Jersey and employs approximately 200 people. Bihler of Germany is a large manufacturer of stamping and assembly equipment which began expansion into the United States in the 1970's. The arrangement between Bihler of Germany and Bihler USA is that Bihler USA resells base machines to its customers. ${ }^{9}$ At customer request, Bihler USA may also supply applications engineering solutions to produce specific products.

Bihler USA faces the traditional risk of a machine tool builder operating in a volatile environment. They face an additional risk due to the

\footnotetext{
${ }^{9} \mathrm{~A}$ "base machine" is a machine which does not come with the tooling and fixturing necessary to produce specific products. This tooling must be added by the customer, the machine tool builder, or a third party before manufacturing can take place.
} 
nature of their business in the U.S. Many customers who purchase turn-key systems from Bihler have a difficult time operating the equipment at full speed and efficiency. This has led to disputes with several customers. It is Bihler's contention that these companies have under-invested in operator training, noting that they consider an operator fully competent only after five years of continuous training, while their customers expect people with several weeks or months of training to master the equipment. Conversely, many customers contend that Bihler has under-invested in interface design, rendering the equipment unnecessarily difficult to operate. Rejecting the option to invest more heavily in user interfaces, Bihler has instead chosen to migrate toward contract manufacturing. By manufacturing high volume products as well as machines and machine tooling, Bihler has stabilized its revenue base, allowing it to maintain its role as a traditional supplier of machine tools. Bihler managers have a specific point of view about retaining the ability to build tooling:

Toolmaking is hard. Sometimes we make money, sometimes we lose. That is not the issue. We want the experience. ${ }^{10}$

Manufacturing both products and machines ensures that the company maintains a broad range of capabilities.

It will be interesting to observe other builders of machine tools to see if they continue to pursue their traditional business of selling only machines and manufacturing systems, or if they also seek to operate in the inherently less volatile environment of high volume manufacturing. Through the cases described above and many others collected over the period from 19921995, the authors have developed several hypotheses about the nature of the machine tool industry. In the next section, we describe these hypotheses.

\section{Hypotheses}

Evidence from the field work done by the MIT Technology Supply Chain Research Project has lead us to propose the following hypotheses about the nature and effects of cyclical volatility upon the machine-tool industry.

${ }^{10}$ Field notes, Geoffrey Parker, May 27, 1994. 
These hypotheses would also seem to apply to other capital-goods manufacturers for the most part.

\section{H1: The extreme amplification of cyclical volatility facing the machine tool industry is inherent due to the capacitization of the industry to the capital deterioration rate of its customers. This effect is fundamentally more severe than the Beer-Game effect.}

The classic Beer-Game effect results from an amplification in orders along a supply chain from retailer to distributor to wholesaler to manufacturer. As the retailer receives an increase in orders, the distributor will not increase its own orders immediately. (The distributor could increase its reaction rate to retail order changes, but this might make it over-sensitive to a possibly noisy input.) By the time the distributor adjusts its own order rate to the new retail order rate, it will have suffered a reduction a significant inventory reduction. Replacing the depleted inventory will require an overshoot in distributor orders above that needed to satisfy the new equilibrium. This order overshoot is then passed further up the chain of distribution creating the "Beer-Game" effect which was first described by Forrester. ${ }^{11}$ Further work on the Beer-Game effect has been done by Sterman ${ }^{12}$ and Lee, Padmanabhan, and Whang among others. ${ }^{13}$

The machine-tool effect, while similar to the Beer-Game effect, has a different chain of causality. Assume a machine-tool customer replaces ten percent of its capacity each year on average. If it suddenly experiences a sustained five percent increase in consumer orders, it will have to increase its capacity by five percent to meet the new demand. This five percent increase, in addition to the ten percent needed in any case for the replacement of

\footnotetext{
11 See P. M. Senge, The Fifth Discipline, Doubleday-Currency Press, Chapter 3, 1990 or J. D. Sterman, "Modeling Managerial Behavior: Misperceptions of Feedback in a Dynamic Decision Making Experiment," Management Science, (35) 3: 321-339, March, 1989 for more complete descriptions.

12 Strictly speaking, the Beer-Game effect is also due in large part to poor adjustment of supply lines. This poor adjustment of supply lines by managers has been experimentally demonstrated by J. D. Sterman in an analysis of beer-game results in the article cited previously. Sterman also detected the same behavior in an analysis of results from the long-wave game in "Misperceptions of Feedback in Dynamic Decision Making," Journal of Economic Behavior and Organization, (6) 17-53, 1985.

13 "Poor" supply-line adjustment also can arise from "rational" solutions by customers to rationing of machine-tool production. See H. Lee, P. Padmanabhan, and S. Whang, "Information Distortion in a Supply Chain: The Bullwhip Effect," Stanford University Working Paper, 1994.
} 
deteriorating capital, will force the customer to place a capital order equivalent to fifteen percent of its capacity. This increment represents a fifty percent increase over the customer's average past order. The machine-tool maker thus faces a proportional increase in demand amplified ten-fold from what the customer received. This amplification is much greater than that typically encountered with the Beer-Game effect-at least on a per-stage basis. Fundamentally, the difference in amplification between the two effects is a direct result of different causal mechanisms. The Beer-Game effect results from distortions in ordering information induced by inventory stocks. The machine-tool effect, on the other hand, is a result of the equilibrium capacity of a capital vendor being based on the capital deterioration of its customers.

\section{H2: As cyclical volatility of orders drops, so too does the average employment of the machine-tool supplier.}

Evidence from our fieldwork indicates that the capacity of a machinetool firm is primarily determined by the size and experience of its labor force. During an upturn, the machine-tool vendor experiences a dramatic upswing in orders. To meet this demand, it will eventually hire more employees. New employees are less efficient and require training time from experienced employees. So the supplier needs to hire more of the new employees than it would if they were already trained. (The trained workers unemployed by the previous downturn are typically lost to the industry. ${ }^{14}$ ) During the next downturn, the workforce is downsized again. The cycle begins with the next upturn, when the supplier again has to hire more new employees than it would in a less volatile environment. On the average, a firm in a more cyclically volatile environment will end up having a larger workforce than it would otherwise.

\section{H3: An increase in the volatility customer orders will lead to a decrease in the average experience level of machine-tool maker employees.}

An increase in the volatility of customer orders will lead to an increase in the volatility of its machine-tool orders by the customer. In aggregate, this

14 Observations from our fieldwork indicate that these skilled employees are typically snapped up by firms outside the machine-tool industry before the machine-tool industry can recover. 
increasing cyclical volatility will create more severe downturns for the machine-tool supplier. It will be forced to terminate a greater portion of its experienced employees on the average than in a less volatile environment. This will reduce the average workforce experience.

H4: The average employment of a machine-tool supplier can be reduced by a) allowing larger backlogs to develop (decreasing the sensitivity of capacity acquisition to innovations), or b) stockpiling machine-tools in anticipation of future upswings.

Both of these solutions create an effective smoothing of the order flow as seen by the machine-tool maker's production sector. Alternative A was a traditional solution of the machine-tool industry which became problematic in the late 1970s. ${ }^{15}$ During this period, Japanese firms dramatically undercut American firms' delivery delays resulting in large losses of market share by domestic makers. On the other hand, Alternative B has limits because only standardized machine-tools can be effectively stockpiled. American machinetool customers seem to prefer turn-key solutions, however, which forces a make-to-order approach upon the vendors. ${ }^{16}$ Also, technical improvements can create the risk of stockpiled machine-tools becoming obsolete.

\section{H5: Reducing production lead-time will reduce machine-tool supplier backlogs and benefit the entire supply chain.}

Production lead-time in the machine tool industry is quite long, but a great majority of that time results from coordination issues and the applications engineering necessary to produce specific products with machines. ${ }^{17}$ Making the machine tools themselves requires considerably less time. Basic business process re-engineering methodology would suggest that lead-times in such a case could be substantially reduced. This reduction would cut work-in-progress for the machine-tool supplier. At the same time, it would allow the machine-tool customer to better match capacity to demand.

15 Max Holland, When the Machine Stopped, Harvard Business School Press, 1989.

16 Observations from our fieldwork.

17 More results from our fieldwork. 


\section{H6: Improvements in customer ordering practices (smoother order rates) are a much-higher leverage policy than similar improvements in internal machine-tool supplier policies.}

While improvements in machine-tool supplier management practices are essential, the highest leverage for firms such as General Motors, Boeing, or other companies may lie in smoothing their own machine-tool order flows. Typical corporate practice is to cut capital orders at the first hint of a downturn and then to make up for this gap in capacity during a subsequent upturn. While this policy might be good for one small customer considering its own interest myopically, in aggregate such practices only aggravate the machine-tool effect felt by the supplier. For a firm such as General Motors which has significant market power, such a policy may not make even myopic sense. For instance, one advanced manufacturing manager at General Motors has suggested giving machine-tool vendors a subsidy during down-turns to keep their suppliers afloat. ${ }^{18}$ While he was referring to a combination of pressures from both cyclical volatility and technology shifts, it is still instructive that a large company might consider aiding some capital equipment suppliers in this manner. In this case, consciously avoiding sudden shifts in machine tool orders might provide one form of inexpensive assistance, as the resulting reduction in volatility would tend to reduce machine-tool supplier average costs. Manufacturing firms could conceivably lower their capital equipment expenditures through more level ordering since equipment may be "on sale" during industry downturns.

\section{Methodology \& Model Description}

In order to examine these hypotheses, we will build a simulation model of a typical machine-tool order chain. Because of the non-linearities, feedback, and delays involved, we will base the model on the system dynamics methodology. ${ }^{19}$ This relatively sparse model will not seek to capture the broad and rich dynamics inherent in the machine-tool industry ${ }^{20}$

\footnotetext{
18 From conversation with Mr. Sam Wennberg, Delco Electronics Advanced Manufacturing Manager on $12 / 2 / 94$.

19 See Forrester, or G. P. Richardson and A. L. Pugh, Introduction to System Dynamics Modeling with Dynamo, MIT Press, 1981.

20 See Kallenberg.
} 
but rather to demonstrate convincingly the essential dynamics relevant to our hypotheses. As such, some explanatory accuracy will be traded for ease of communication. Specifically, order cancellations and market-share variation will be excluded. However, we will show that the model conforms to general expectations of machine-tool industry behavior. The firm structure for the model is a simplification of the "standard" system dynamics firm model21 adapted to create two interacting firms, a machine-tool customer and a machine-tool supplier (next page.) Once the model is built several experiments will be performed to test the hypotheses described above.

(see figure 5.1, end of document)

\section{Model Overview}

We present here a quick overview of the model. A detailed description of the equations is included in the appendix. Refer to Figure 1 which contains a policy diagram of the model. For convenience we will refer to the machinetool customer from this point on as the widget maker, and the machine-tool supplier as the machine maker. In the diagram, rectangles represent stocks. Stocks represent variables that can accumulate, such as a bank balance or a bathtub full of water. In control engineering terminology, they represent the states of the system. The circles with stylized valves represent flows into or out of the stocks. Concrete examples of flows would be bank deposits, withdrawals, or water entering a bathtub through a faucet or leaving through a drain. The unattached circles are auxiliary equations which clarify structural representation. The circles with lines through them are managerial policies.

The mechanics of managerial policies included in the model are typical of the bounded-rationality approach used in system dynamics. ${ }^{22}$ However, some of the more egregious "irrationalities" revealed by system dynamics research such as supply-line discounting will be excluded. This exclusion will prevent confounding of the effects of "irrational" policies with those inherent in the structure of the machine-tool customer-supplier relationship.

\footnotetext{
21 See J. M. Lyneis, Corporate Planning and Policy Design: A System Dynamics Approach, Pugh-Roberts Associates, Cambridge, MA, 1980.

22 See J. Morecroft, “Portraying bounded Rationality," Omega, (11): 131-142 for theoretical justification of this approach.
} 
(see figure 5.2, end of document)

In the model the widget maker receives a widget order rate that is used over time to develop a forecast of future widget demand. The method used for this forecasting is simple exponential smoothing. The widget maker then calculates how many machines (manufacturing capacity) will be required to meet the forecast demand. The result of this calculation is then added in to the machine orders required to replace deteriorating capital. The widget maker passes this order rate on to the machine maker who goes through a similar forecasting process to determine its capacity. This is then translated into a desired number of employees and a desired hiring or termination rate. ${ }^{23}$

Meanwhile the machine maker, a make-to-order firm, is using its current employees to produce the machines requested by the widget maker. The machine maker is constrained both by its effective workforce and by its ability to vary production through overtime and furloughs. Once these machines are produced, they are shipped to the widget maker where they begin to make widgets. The number of widgets produced is constrained by its number of machines and its production flexibility as shown in Figure 2. Its production rate is, however, also influenced by inventory in the familiar Beer-Game effect.

The capacity of the machine maker is ultimately determined by its employees. However, not all employees are the same. When an employee enters the organization, he enters a period of apprenticeship during which he is both a) less productive than a trained employee and b) requires instruction from trained employees which could otherwise be spent on production. After a certain number of years in service, the employee leaves the organization at which time a replacement is hired. This rate of attrition is analogous to machine deterioration in the widget maker. However, it can be accelerated by forced termination if the rate of attrition is insufficient to produce the cutbacks required by the capacitization policy.

23 We are assuming a Leontief production function for both widget and machine maker. The machine maker is always assumed to have enough capital, and is thus constrained solely by its employees. The widget maker is always assumed to have enough employees, and is constrained by its machines. 
In Figure 2 is shown the production system of the widget maker. The widget maker is assumed to be a make-to-stock firm. Parts at the beginning of the chain are based on the expected widget demand rate and any corrections necessary to bring parts inventory up to its desired level. The expected order rate is another exponentially weighted smoothing, albeit over a much shorter time horizon than that used for the capacity forecasts. Parts on order are shipped to the widget maker's parts inventory where they are converted into finished widgets. The production rate is determined by the expected order rate as constrained by its capacity, which is a function of its machines. Finished widgets are shipped to the widget customer as required.

(see figure 5.3, end of document)

\section{Constants Used in Base Model ${ }^{24}$}

Base widget order rate

Time horizon for widget order forecasts

Factor productivity of machines

Factor productivity of labor

Capacity utilization saturation

Machine manufacture lead-time

Time horizon for machine forecasts

Average employee tenure

Time to hire employees

Time to terminate employees

Base time to train employees

Saturation time to train employees

Relative productivity of rookie employees

Time horizon for forecasting widget order rate for production

Time to correct finished widget inventory

Desired finished widget inventory coverage

Widget parts shipping delay

Time to correct widget parts assembly inventory coverage

Desired widget parts assembly inventory coverage

\begin{tabular}{|c|c|}
\hline WOR $^{\mathrm{a}}$ & 1000 widgets/month \\
\hline $\mathrm{TFW}^{\mathrm{b}}$ & 18 months \\
\hline $\mathrm{K}^{\mathrm{a}}$ & 1 widget/machine/month \\
\hline $\mathrm{L}^{\mathrm{a}}$ & 1 machine/month/employee \\
\hline $\mathrm{f} 1(1.6)$ & $140 \%$ \\
\hline MLT $^{b}$ & 18 months \\
\hline TFM & 18 months \\
\hline $\mathrm{AET}^{\mathrm{b}}$ & 10 years \\
\hline THE $b$ & 3 months \\
\hline TTE $^{b}$ & 3 months \\
\hline BTTRE b & 5 years \\
\hline $\mathrm{f} 2(1)^{*}$ BTTRE $b$ & 10 years \\
\hline$R P b$ & 0.5 \\
\hline
\end{tabular}

TFWP $\quad 6$ months

TCFWI 2 months

DFWIC 3 months

WPSD 2 months

TCWPI $\quad 2$ months

DWPIC $\quad 2$ months

24 Values for variables marked with "a" are arbitrary and have no effects on model results. Those marked with " $b$ " are drawn from experience and interviews gained from our fieldwork. These " $b$ " values have been chosen to err on the side conservatism with respect to the dynamics described in the paper. That is, other reasonable values would tend to enhance the dynamics herein described. Those values unmarked are drawn from Lyneis and represent stylized values based on data from Pugh-Roberts Associates, a large system dynamics consulting firm, and the MIT System Dynamics Group. 
The reference rookie fraction (RRF) and equilibrium employee effectiveness (EEE) are both set by the model from other parameters in order to begin the simulation in equilibrium.

\section{Simulation Results}

\section{Comparison of simulated with actual data}

Shown below in Figures 3 and 4 are the simulated and actual yearover-year fractional changes in Constant 1987 US Dollar machine-tool orders and sales. The input order rate to the model came from the Statistical Abstract of the Untied States' Industrial Production Index-Manufacturing for the years 1960 to 1992. The actual machine-tool industry responses for the same period are drawn from The Economic Handbook of the Machine Tool Industry. The two are then compared in the same figures. Note that, while this model is quite simplified and the parameters are "untuned," the gross amplitude and phase responses are relatively accurate reflectors of aggregate industry behavior. This is particularly true after the initial warm-up period of 1960 to 1965 is excluded. Thus the model seems a reasonable approximation of average machine-tool industry response to fluctuations in the order stream experienced by machine-tool customers.

(see figure $6.1 \& 6.2$, end of document)

\section{Response of the machine supplier to a step-input}

In Figure 5 below, the widget order rate, the machine order rate, and the machine production rate begin in equilibrium. At time $=10$ months, an $8 \%$ step increase occurs in the widget order rate. The widget maker's forecast demand immediately begins to climb to the new equilibrium widget order rate. As it increases, so too does the machine order rate. The machine maker is, however, constrained by a lack of employees with which to produce the requested machines. It is also reluctant to add employees, and does not bring enough on-line to begin to reduce its backlog until time $=2.5$ years (Figure 6). In fact, so many new employees are hired, that there is a very slight employee cutback around time $=7$ years (Figure 7 ). This happens because the employees brought in to meet the backlog in years one through three have driven the 
rookie ratio up from its equilibrium value. As the ratio returns to its equilibrium value, the effective pool of labor increases, creating a surplus of machine employees. This hiring and termination behavior generates the characteristics typically associated with the machine tool industry: Lagged and amplified response of the machine order rate to widget order rate changes, and a somewhat more lagged, but less amplified response in the machine production rate. This systemic behavior constitutes our hypothesis of the causal factors behind the machine-tool hypothesis.

(see figure 6.3, $6.4 \& 6.5$, end of document)

\section{Comparison with the Beer-Game Effect}

A comparison of Beer-Game and Machine-Tool responses to the $8 \%$ step increase in the widget order rate is presented below in Figure 8. The Beer-Game effect in this model is roughly about a quarter of the machine-tool effect at their respective maxima under the base assumptions of the mode. This result tends to confirm Hypothesis 1. In fact, we have used somewhat conservative assumptions for the delays involved in the widget maker production sector; so in reality the comparison between the two effects is

probably even more dramatic than here presented. What is interesting is that many machine-tool vendors face both these effects, because many are machine-tool suppliers to parts suppliers. For example, Cincinnati Milacron supplies machine tools to Eaton, which in turn produces parts for General Motors.

(see figure 6.6, end of document)

\section{Hypothesis 2: Average Machine-Tool Maker Employment}

The variations in capacity resulting from, respectively, a $40 \%$ peak-topeak, an $8 \%$, and a $0 \%$ peak-to-peak sine wave widget order rate are shown below in Figure 9. (From here on, we will refer to the $40 \%$ peak-to-peak sine wave widget order rate input as the $40 \%$ input. The $8 \%$ peak-to-peak sine wave input will be referred to as the $8 \%$ input and the $0 \%$ peak-to-peak sine wave as the equilibrium input. See Figure 10.) While the average machine maker effective employees (which is equivalent to capacity in this model) in all three cases is 10.0 employees, the average total machine maker employees 
increases with cyclical volatility as shown in Figure 11. The average total employees range from 10.0 employees under no cyclicality to 11.8 employees under a $40 \%$ input. Hence, while an increase in widget order volatility does not lead to an increase in machine-maker capacity, it does create an increase in average machine maker employment. Put another way, the machine maker's employee productivity drops with increasing volatility. Thus, Hypothesis 2 is corroborated by the model.

(see figure 6.7, $6.8 \& 6.9$, end of document)

\section{Hypothesis 3: Average Machine-Tool Maker Employee Experience}

The source of decreasing productivity under increasing volatility described above comes from an increase in the rookie employee fraction (Figure 12). ${ }^{25}$ Under a $40 \%$ input, the rookie employee percentage climbs from the equilibrium $33 \%$ up to $47 \%$. This increase results from cutbacks of experienced employees during downturns. (See Figure 13. The outputs from the equilibrium and $8 \%$ inputs do not rise above zero.) When the upturns finally arrive, the machine maker has lost experienced employees which cannot be easily replaced from hiring "off the street."

(see figure $6.10 \& 6.11$, end of document)

\section{Hypothesis 4: Cost reduction through backlogs and stockpiling}

Backlog management can be accomplished simply by lengthening the time horizon to forecast machine order demand (TFM). While this will not decrease capacitization for the reasons discussed under Hypothesis 2, an increase in TFW from 18 to 24 months will decrease machine-maker employment by reducing experienced employee cutbacks during downturns. The machine maker employment dropped from 11.8 employees down to 11.2 in response to the $40 \%$ input.

25 In reality of course, employees come in a continuous range of experience. The rookie fraction is in general a reasonable proxy for experience, but it is insensitive at the lower and higher range of volatilities, when all the employees become, respectively, either experienced employees or rookies. This is shown by the tiny increase in the average rookie fraction resulting from a $4 \%$ increase in widget order volatility. This negative impact understates the decrease in experience that would be suffered by a real firm under such conditions. 
Stockpiling can be simulated by increasing the indicated machine production rate by $20 \%$ over what it otherwise would be. Machine-maker capacitization is again unaffected by this change in model parameters. The average backlog over the simulation run is, however, reduced from 151 to 129 machines when facing the durable goods input (Figure 14). This improvement could theoretically be turned into a reduction in employees, although given the large backlog, this might not be the most rational policy. In short, both parts of this hypothesis are confirmed.

(see figure 6.12, end of document)

\section{Hypothesis 5: Reducing Machine Production Lead-Time}

Cutting the machine manufacture lead time (MLT) from 18 down to 9 months when facing a $40 \%$ input affects the machine maker in this model other primarily by cutting the machine order backlog in half (Figure 15). (Presumably, cancellations would also be reduced it these were represented in the model.) On the other hand, this lead time reduction creates an increase in widget-maker capacity volatility (Figure 16). This results from a decrease in machine order smoothing through backlogs as discussed previously. Thus, while a decrease in lead-time is presumably beneficial to the machine-tool maker, it does create some possibly deleterious side-effects at the widgetmaker level.

(see figure $6.13 \& 6.14$, end of document)

\section{Hypothesis 6: Leverage of Widget-Maker Policies vs. Machine-Maker's}

Fundamentally, the fulcrum of the machine-tool effect is the machine order rate determined by the widget maker. In this model, as in reality, the machine maker's policies have very little effect on the machine order rate. Compare the effects of an increase in the time to forecast widget demand (TFW) from 18 to 36 months with that of a similar policy change at the machine-maker level (TFM goes from 18 to 36 months). (The input widget order rate series is the $40 \%$ series.) Machine order and shipment rates are unaffected by a change in TFM, but a change in TFW decrease volatility substantially in both series (Figures 17 and 18). The only effect comparable 
between the two parameter changes a decrease in the machine maker's rookie fraction (Figure 19).

(see figure 6.15, $6.16 \& 6.17$, end of document)

\section{Discussion}

Using a sparse model, we have replicated much of the behavior seen in the industrial world in which machine tool companies must operate. This model has allowed us to test and confirm many of our hypotheses; albeit in the restricted model world we have constructed. Two of the results stand out. Even though machine tool builders can do little to reduce their production volatility through choice of forecast rule, a longer view of the market leads companies to retain more of their skilled workforce. This is often cited as one of the advantages that European and Japanese companies have enjoyed: lower skilled employee turnover. The second, and most important result is that machine tool customers can do a great deal to reduce the volatility for machine tool builders through their choice of order forecast rule. Companies which use a longer horizon over which to forecast orders tend to impose less of their own volatility upon their supply base.

A general observation of the authors is that most German and Japanese manufacturing firms consider applications engineering and system integration to be core capabilities which must be done in-house. This view has changed somewhat in recent years with the dramatic economic downturn in those countries, but it remains a general observation. Addressing the benefits and costs of this practice lies outside the scope of this paper, but one result of higher customer capability is that machine tool builders are able to stock more standardized machines, which the customers can then customize to their own requirements. ${ }^{26}$ This implies that the stockpiling option is more feasible for those companies who have customers with highly capable internal engineering staffs.

\footnotetext{
${ }^{26}$ In general, there is anecdotal evidence which suggests that performing applications engineering and system integration "in house" makes a company better able to pursue successful concurrent engineering projects and to undertake continuous improvement projects. The trade-off for these capabilities is the higher fixed costs of the personnel necessary to perform these functions.
} 
In an ideal environment for machine tool builders, customers would take the lead in supporting suppliers over the long term to flatten out the ill effects of cyclicality, and to encourage innovation and continuous process improvements. However, many industrial customers do not take this leadership role, perhaps understating the effect they can have on the stability of the technology suppliers upon which they rely. One of our central recommendations is that machine tool suppliers take the lead in calling for and creating new relationships with their customers, and take part in institutionalizing them as standard practices in the industry. The competitive conditions of the new, flexible manufacturing environment no longer allow suppliers to get by with simply listening to their customers. Machine tools have become so complex that in some cases they can only be serviced and maintained at full operational capacity by people who were involved in their development and construction. Users often have insufficient expertise or experience to anticipate their needs, or even articulate them. Suppliers will have to work closely with their customers in order to jointly instruct and learn from one another, so that machine tool users to get the most out of their equipment. This means joint commitment of time and resources to long-term partnerships for equipment development and sourcing. The payoff for customers will be suppliers better able to devote resources to research, development and innovation, first-rate equipment tailored to their specific needs - aggressively supported and maintained, and as a result of these benefits, greater productivity. The payoff to suppliers is advance knowledge of customer needs, stronger user pull on innovation, and greater stability as customers pursue policies designed to reduce supplier volatility.

A number of companies are already undertaking the construction of new cooperative relationships. These relationships can be tracked, their relative effects measured, and then compared to the performance of more traditional, arms-length relationships. For example, customer-supplier pairs can be evaluated on performance criteria such as level of $R \& D /$ innovation, financial stability of the supplier, delivery time, product support, and productivity of tools in use. If one considers these relationships to be solutions to fundamental problems encountered by firms, such as uncertainty and risk, much work remains to be done in developing a taxonomy of the particular uncertainties and risks firms face in developing a sourcing 
manufacturing equipment. Partnering and collaborative development of manufacturing equipment may not be the optimal strategy for all industry players. Some firms, such as Fadal Engineering Inc., appear to be having success within the framework of more traditional relations. ${ }^{27}$ But others, such as Eaton Corporation with Cincinnati Milacron, United Technologies with Giddings \& Lewis, have decided to change the structure of relations between buyers and suppliers of machine tools. Where Fadal seems to be successful in using traditional market institutions and strategies that are familiar in the industrial organization literature, the new supplier partnerships are much less well understood. Much work remains to be done in classifying the problems faced by machine tool buyers and suppliers, and the particular institutional solutions they select in addressing those problems. A useful contribution could therefore be made by building a taxonomy of these relations, the problems they seek to address, and the conditions under which they succeed or fail.

Another, related area for further research involves issues surrounding the nature of organizational change and learning. Firms deploy resources both internally and externally to gather information about their markets and relationships. What makes some firms better at this than others? In studying buyer-supplier relations, a number of observers have taken up the analytical framework of "exit, voice, and loyalty." Exit refers to a departure from a relationship, voice to signaling that the relationship is going awry, and loyalty to the factors that help delay exit long enough for voice to help get the relationship between buyer an supplier back on track. Missing from the current literature is an analysis of "listening," or learning, and the factors that make some companies learn much more effectively than others. In these relationships, we hope to study the development of "learning organizations," by evaluating the participants on their development and commitment to the technology and culture of collaboration and information exchange. Another fruitful area of research would be the construction of simulation models which can help to forecast the magnitude and duration of the cycles faced by firms at various locations along the technology supply chain.

${ }^{27}$ Los Angeles Times, 12/23/93, pp. D1. 


\section{References}

M. Holland, When the Machine Stopped, Harvard Business School Press, 1989.

R. Kallenberg, Analysis of Business Cycles in the U.S. Machine Tool Industry Using the System Dynamics Method, Unpublished Masters Thesis, Rheinisch-Westfaelische Technische Hochschule Aachen, July 1994.

H. Lee, P. Padmanabhan, and S. Whang, "Information Distortion in a Supply Chain: The Bullwhip Effect," Stanford University Working Paper, 1994.

P. M. Senge, The Fifth Discipline, Doubleday-Currency Press, Chapter 3, 1990.

J. D. Sterman, "Modeling Managerial Behavior: Misperceptions of Feedback in a Dynamic Decision Making Experiment," Management Science, (35) 3: 321339, March, 1989. 


\section{Appendix A. Model Equation Descriptions}

Widget-Maker Machine Equations

$$
\begin{aligned}
& \mathrm{d}(\mathrm{M})=(\mathrm{MAR}-\mathrm{MDR}) * \mathrm{dt} \\
& \mathrm{d}(\mathrm{FWD})=\mathrm{dt} *(\mathrm{WOR}-\mathrm{FWD}) / \mathrm{TFW} \\
& \mathrm{DM}=\mathrm{K} * \mathrm{FWD} \\
& \mathrm{MOR}=\max (\mathrm{DM}-\mathrm{M}+\mathrm{MDR}, 0)
\end{aligned}
$$

where

$$
\begin{aligned}
& \mathrm{M} \quad \text { = number of widget machines (machines) } \\
& \mathrm{MAR}=\text { machine acquisition rate (machines } / \text { month) } \\
& \mathrm{MDR}=\text { machine deterioration rate (machines } / \text { month) } \\
& \mathrm{dt} \quad=\text { time step (months) } \\
& \mathrm{FWD}=\text { forecast widget demand (widgets } / \text { month) } \\
& \mathrm{WOR}=\text { widget order rate (widgets } / \text { month) } \\
& \mathrm{TFW}=\text { time horizon to forecast widget order rate (months) } \\
& \mathrm{DM} \quad=\text { desired machines (machines) } \\
& \mathrm{K} \quad=\text { factor productivity of machines (widgets } / \text { month } / \text { machine) } \\
& \mathrm{MOR}=\text { machine order rate (machines } / \text { month) }
\end{aligned}
$$

The number of machines in a given period is increased by acquisitions and decreased by deterioration (depreciation). The forecast widget demand is an exponentially weighted moving average of past demand. Desired machines are the number of machines required to satisfy the forecast widget order rate. Hence the machine order rate covers the gap between desired and present machines as well as the deterioration of present machines in each period. In reality, the widget maker will cancel some of its machine orders during a downturn. However, for the sake of simplicity in our model, the widgetmaker cannot do this. ${ }^{28}$

\section{Machine Maker Production Equations$$
\mathrm{MStR}=\mathrm{MOR}
$$

\footnotetext{
28 In simulation runs in which cancellations were permitted, cyclical volatility increased in comparison with simulation runs based on this assumption.
} 


$$
\begin{aligned}
& \mathrm{C}=\mathrm{L} * \mathrm{EE} \\
& \mathrm{IMPR}=\mathrm{MOB} / \mathrm{MLT} \\
& \mathrm{CU}=\mathrm{f} 1(\mathrm{IPR} / \mathrm{C}), \mathrm{f} 1(0)=0, \mathrm{f} 1(1)=1, \mathrm{f} 1 \text { (infinity) < infinity } \\
& \mathrm{f1} 1^{\prime} \geq 0, \mathrm{f1}^{\prime \prime} \leq 0 \\
& \mathrm{MShR}=\mathrm{C} * \mathrm{CU} \\
& \mathrm{d}(\mathrm{MOB})=(\mathrm{MStR}-\mathrm{MShR}) * \mathrm{dt}
\end{aligned}
$$

where

$$
\begin{array}{ll}
\text { MStR } & =\text { machine start rate (machines } / \text { month) } \\
\mathrm{C} & =\text { machine maker base capacity (machines } / \text { month) } \\
\mathrm{L} & =\text { factor productivity of labor (widgets/month/employee) } \\
\mathrm{EE} & =\text { effective employees (employees) } \\
\mathrm{IMPR} & =\text { indicated production rate (machines/month) } \\
\mathrm{MLT} & =\text { machine manufacture leadtime (months) } \\
\mathrm{CU} & =\text { capacity utilization (dimensionless) } \\
\mathrm{MShR} & =\text { machine shipment rate (machines } / \text { month) } \\
\mathrm{MOB} & =\text { machine order backlog }
\end{array}
$$

The machine maker is assumed to be a make-to-order supplier (which seems true of most suppliers to American machine-tool customers according to MIT TSC research). The machine start rate at the machine maker is equal to the machine order rate coming from the widget maker. The baseline capacity of the machine maker is dependent on the number of effective employees it has. Effective employees is the number of employees adjusted downward for the lesser productivity of rookie employees. The indicated production rate is the number of machines that could be produced given an unlimited labor pool. If no overtime is required, this will become the production rate of machines, which is the Machine Shipment Rate. If, however, overtime is required, production will saturate at some point, assumed in this model to be at less than $50 \%$ over base capacity. As the machines are shipped, the backlog declines.

\section{Machine Maker Forecasting Equations}

$$
\begin{array}{ll}
\mathrm{d}(\mathrm{FMD}) & =\mathrm{dt} *(\mathrm{MOR}-\mathrm{FMD}) / \mathrm{TFM} \\
\mathrm{DE} & =\mathrm{L} * \mathrm{FMD} \\
\mathrm{DCEL} & =(\mathrm{DE}-\mathrm{EE}) / \mathrm{REE}
\end{array}
$$


where

$$
\begin{aligned}
& \text { FMD = forecast machine demand (machines/month) } \\
& \text { MOR = machine order rate (machines } / \text { month) } \\
& \text { TFM = time horizon to forecast machine order rate (months) } \\
& \mathrm{DE}=\text { desired employees (employees) } \\
& \mathrm{L} \quad=\text { factor productivity of employees (machines/month/employee) } \\
& \text { DCEL = desired change in employee level (employees) } \\
& \mathrm{EEE}=\text { equilibrium employee effectiveness (dimensionless) }
\end{aligned}
$$

The machine maker forecasts machine-order demand by exponentially weighting past machine orders. It then determines the number of employees required to satisfy such a demand. Since an inrush of new employees will lower the average effectiveness of the workforce, the change is adjusted upwards. Similarly, an employee cutback will eliminate rookies first, again requiring an adjustment of the desired change's magnitude upwards.

\section{Machine Maker Hiring and Attrition Equations}

$$
\begin{aligned}
& \mathrm{E}=\mathrm{RE}+\mathrm{XE} \\
& \mathrm{EAR}=\mathrm{E} / \mathrm{AET} \\
& \mathrm{RAR}=\mathrm{RE} / \mathrm{AET} \\
& \mathrm{XAR}=\mathrm{XE} / \mathrm{AET} \\
& \mathrm{EHR}=\max (\mathrm{EAR}+\mathrm{ELAR} / \mathrm{THE}, 0)
\end{aligned}
$$

where

$$
\begin{array}{ll}
\mathrm{E} & =\text { number of employees (employees) } \\
\mathrm{RE} & =\text { number of rookie employees (employees) } \\
\mathrm{XE} & =\text { number of experienced employees (employees) } \\
\mathrm{AET} & =\text { average employee tenure (months) } \\
\mathrm{EAR} & =\text { employee attrition rate (employees } / \text { month) } \\
\mathrm{RAR} & =\text { rookie employee attrition rate }(\mathrm{employees} / \text { month) } \\
\mathrm{XAR} & =\text { experienced employee attrition rate }(\mathrm{employees} / \mathrm{month}) \\
\mathrm{EHR} & =\text { employee hiring rate }(\mathrm{employees} / \text { month) }
\end{array}
$$


THE = time to hire employees (months)

A constant fraction of both the rookie and trained employees leave the machine maker voluntarily each year. The machine maker hires new employees to make up for this loss. The attrition rates are not adjusted as with DCEL above, because in equilibrium each hiring's lowering of workforce productivity will be balanced by the completion of a rookie's training.

\section{Machine Maker Employee Termination Equations}

$$
\begin{array}{ll}
\mathrm{EC} & =\max (-\mathrm{DCEL}-\mathrm{EAR} * \mathrm{TTE}, 0) \\
\mathrm{RC} & =\min (\mathrm{EC}, \mathrm{RE}-\mathrm{RAR} * \mathrm{TTE}) \\
\mathrm{RCR} & =\mathrm{RC} / \mathrm{TTE} \\
\mathrm{XCR}= & (\mathrm{EC}-\mathrm{RC}) / \mathrm{TTE}
\end{array}
$$

where

EC = desired employee cutbacks (employees)

TTE = time to terminate employees (months)

$\mathrm{RC}=$ desired rookie employee cutbacks (employees)

$\mathrm{RCR}=$ time rate of rookie cutbacks (employees/month)

$\mathrm{XCR}=$ time rate of experienced employee cutbacks

(employees/month)

Employee cutbacks are determined by how many employees the machine maker wishes to forcibly terminate over and above the natural employee attrition rate. Rookie employees are cut back before experienced employees. The actual cutback rates take place over the time required to terminate employees.

\section{Machine Maker Employment Level Equations}

$$
\begin{array}{ll}
\mathrm{d}(\mathrm{RE}) & =(\mathrm{EHR}-\mathrm{RAR}-\mathrm{RCR}-\mathrm{TR}) * \mathrm{dt} \\
\mathrm{RF} & =\mathrm{RE} / \mathrm{E} \\
\mathrm{TTRE} & =\mathrm{f} 2(\mathrm{RF}) * \mathrm{BTTRE}, \mathrm{f} 2(\mathrm{x} 1 \leq \mathrm{RRF})=1, \quad 1<\mathrm{f} 2(1)<\text { infinity, } \\
\mathrm{TR} & \mathrm{f} 2^{\prime} \geq 0, \quad \mathrm{f} 2^{\prime}(\mathrm{x} \leq 1) \geq 0, \quad \mathrm{f} 2^{\prime}(\mathrm{x} \geq 1) \leq 0 \\
&
\end{array}
$$




$$
\begin{array}{ll}
\mathrm{d}(\mathrm{XE}) & =(\mathrm{TR}-\mathrm{XAR}-\mathrm{XCR}) * \mathrm{dt} \\
\mathrm{EE} & =(\mathrm{RP} * \mathrm{RE}+\mathrm{XE}) / \mathrm{REE}
\end{array}
$$

where

$$
\begin{aligned}
& \mathrm{TR}= \text { training rate of rookie employees into experienced } \\
& \text { employees (employees } / \text { month) }
\end{aligned}
$$

Rookie employees are increased by hirings and reduced by cutbacks, attrition, and graduation into experienced employees. Every month a fraction of employees complete training, becoming experienced employees. The time to train rookies, however, increases with the fraction of rookies in the workforce. As employees are trained, so increases the number experienced employees. Experienced employees are drained by both the attrition and cutback rates.

\section{Widget Production System}

$$
\begin{aligned}
& \text { WSR }=\max (F W I / d t, W O R) \\
& d(F W I)=(W P R-W S R) * d t \\
& D W P R=E W O R+C F W I \\
& W P R=f 1(I W P R / M) \\
& E W O R=(\text { WOR }- \text { EWOR }) / \text { TFWP } \\
& C F W I=(D F W I-F W I) / \text { TCFWI } \\
& \text { DFWI }=\text { EWOR * DFWIC }
\end{aligned}
$$

where

WSR = widget shipment rate (widgets $/$ month)

FWI = finished widget inventory (widgets) 
DWPR $=$ desired widget production rate (widgets $/$ month)

CFWI = correction to adjust widget inventory (widgets/month)

$\mathrm{WPR}=$ widget production rate (widgets $/$ month)

EWOR $=$ expected widget order rate (widgets/month)

TFWP $=$ time horizon for forecasting widgets for production (months)

TCFWI $=$ time to correct finished widget inventory gap (months)

DFWI $=$ desired finished widget inventory (widgets)

DFWIC $=$ desired finished widget inventory coverage (months)

This is the standard beer-game effect model. The widget maker ships what is ordered from the finished widget inventory if available. At the same time inventory is replenished by widget production which is limited by the number of machines on hand. Desired widget production is a function of the expected widget order rate and the need to correct inventory discrepancies. The expected order rate is another exponentially-weighted average of the widget order rate. It is, however, updated more rapidly than that used for determining machine requirements. Inventory discrepancies are corrected over a number of months. Desired finished widget inventory is actually a desired number of months of the expected widget order rate.

$$
\begin{array}{ll}
\mathrm{d}(\text { WPI }) & =(\text { WPAR }- \text { WPR }) * d t \\
\text { WPAR } & =\text { WPOO } / \text { WPSD } \\
\mathrm{d}(\text { WPOO }) & =(\text { WPOR }- \text { WPAR }) * d t \\
\text { WPOR } & =\text { EWOR }+ \text { CWPI } \\
\text { CWPI } & =(\text { DWPI }- \text { WPI }) / \text { TCWPI } \\
\text { DWPI } & =\text { EWOR * DWPIC }
\end{array}
$$

where

$$
\begin{aligned}
& \text { WPI } \quad \text { widgets parts assemblies in inventory (widgets) } \\
& \text { WPAR }=\text { widget parts assembly arrival rate (widgets } / \text { month) } \\
& \text { WPOO }=\text { widget parts assemblies on order (widgets) } \\
& \text { WPSD }=\text { widget parts shipping delay (months) }
\end{aligned}
$$


WPOR = widget parts assembly order rate (widgets/month)

CWPI = correction for widget parts assembly inventory (widgets/month)

TCWPI = time to correct widget parts assembly inventory (months)

DWPI = desired widgets parts assembly inventory (widgets)

Parts assemblies are ordered based on the expected widget order rate and corrections needed to the widget parts assembly inventory. The parts assemblies ordered arrive after a shipping delay. The desired parts inventory is again a function of the expected widget order rate and the desired number of months of inventory coverage. Any parts inventory discrepancies are corrected during ordering over a number of months. The parts assembly order rate becomes the order rate to the parts supplier who observes the BeerGame effect. 
Figure 5.1: Model Market Structure

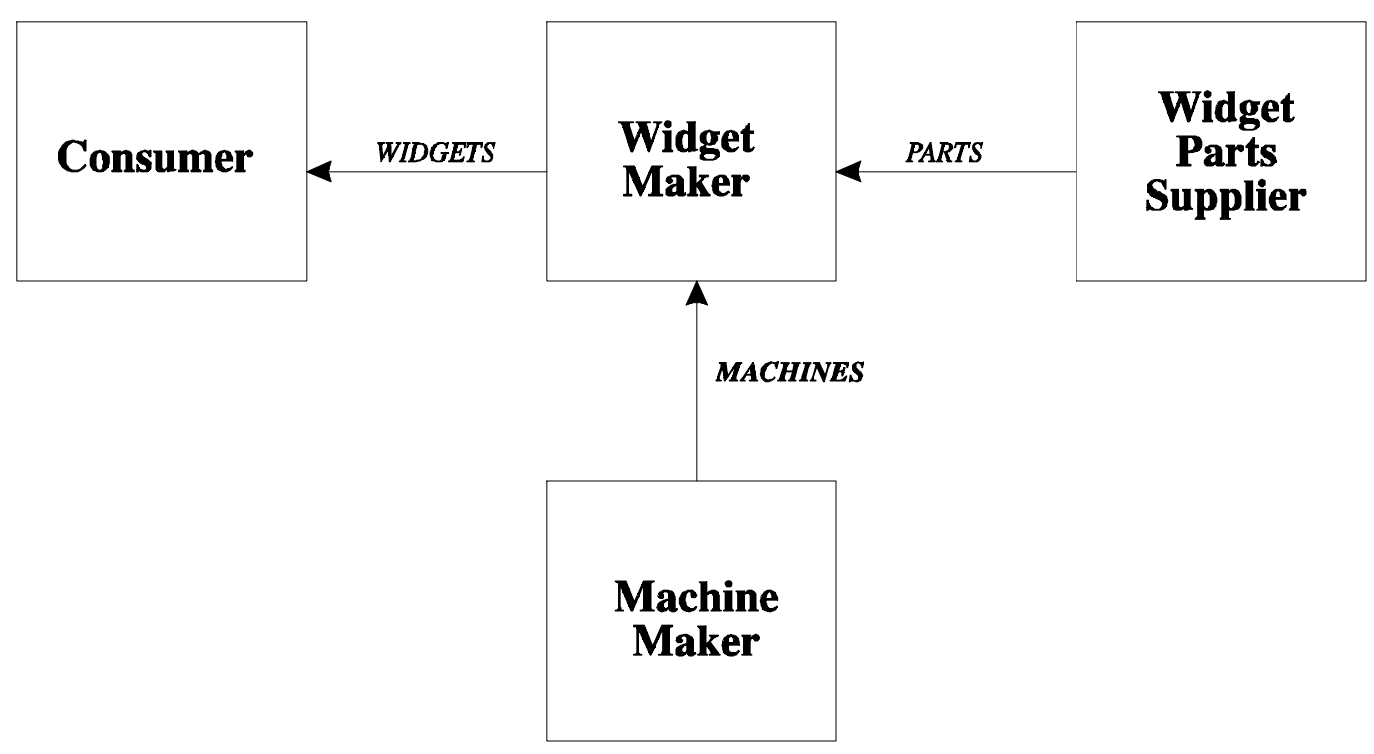

Figure 5.2: Policy Structure Diagram of Main Model

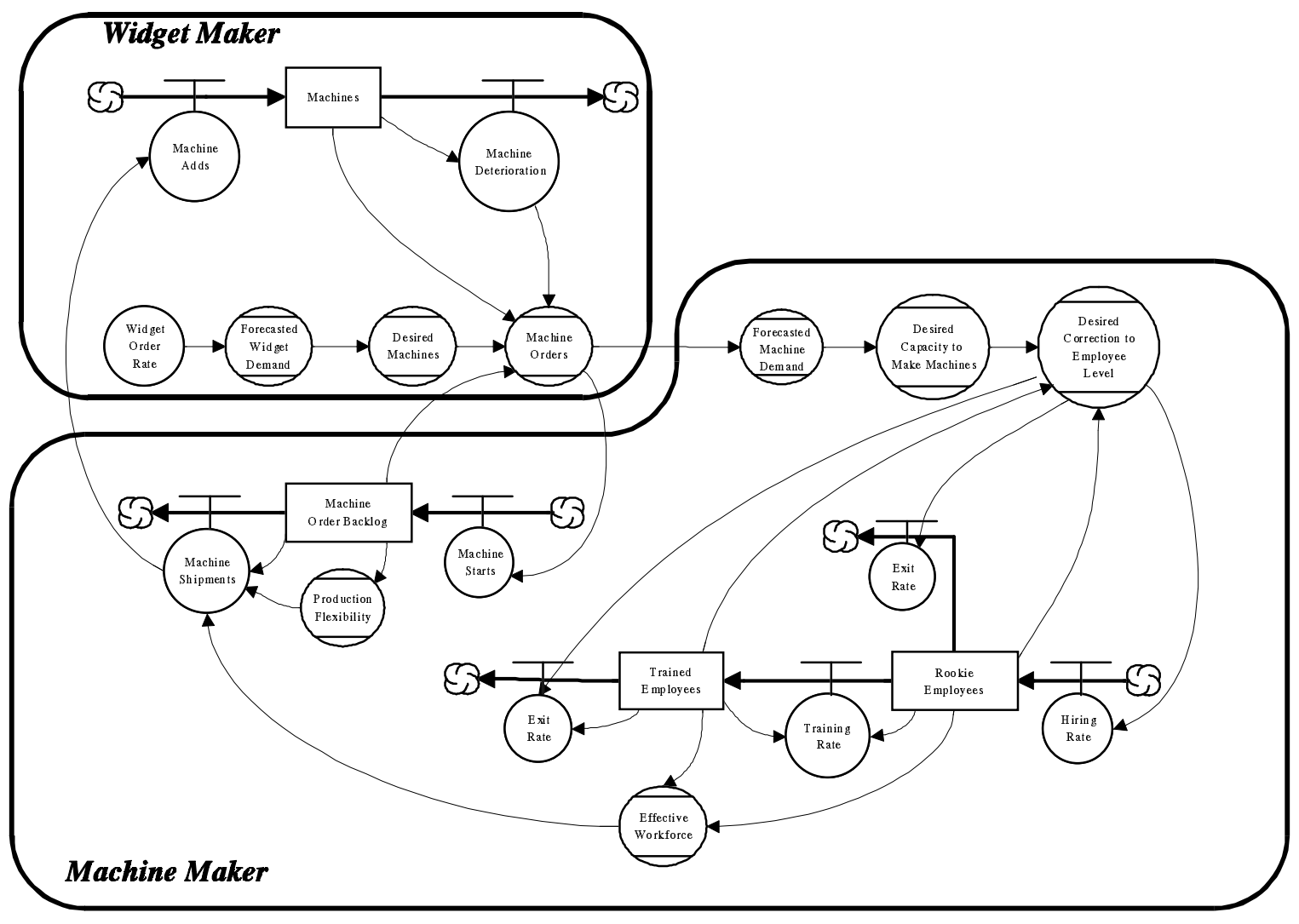

Page 34 
Figure 5.3: Policy Structure Diagram of Beer-Game Model

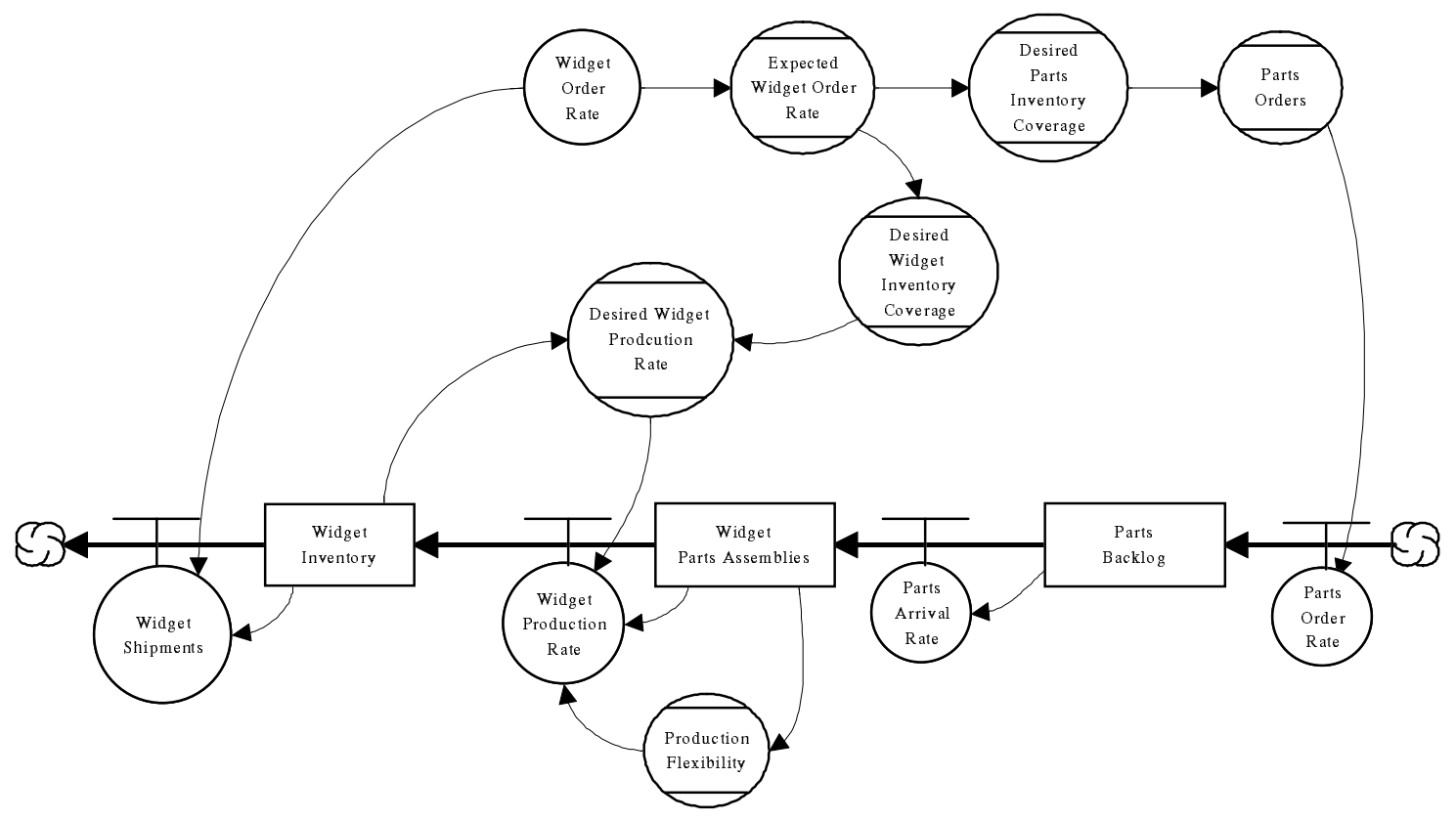

Figure 6.1--Actual vs. Simulated Machine Tool Orders

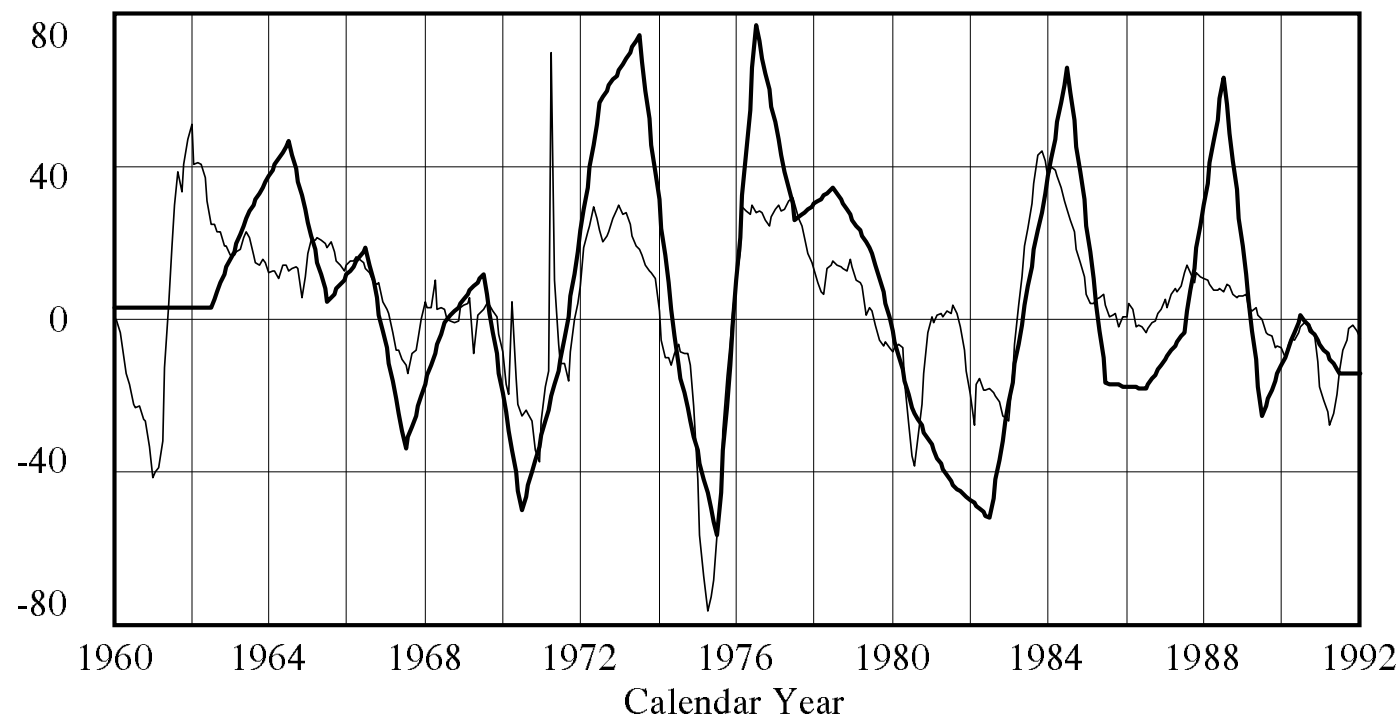

Simulated Percentage Change Year-over-Year Actual $\longrightarrow$ Percentage Change Year-over-Year 
Figure 6.2--Actual vs. Simulated Machine Tool Sales

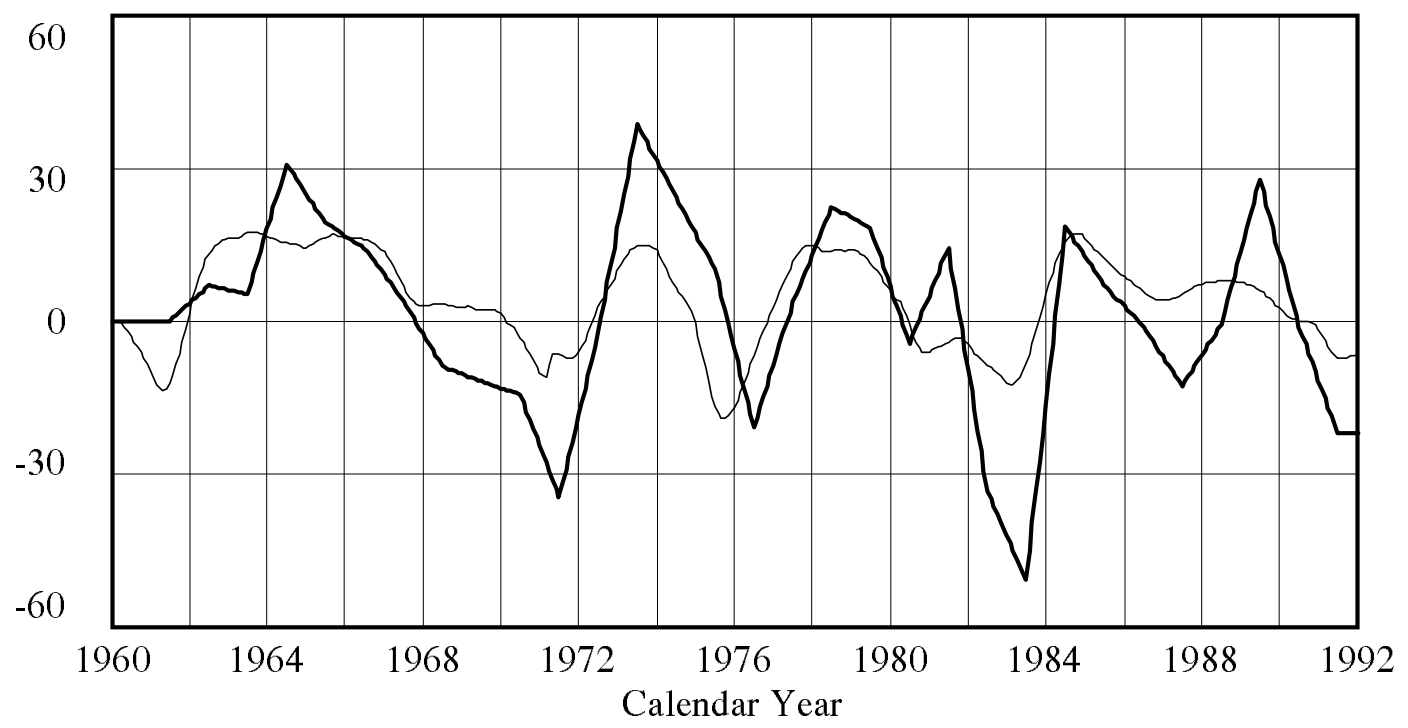

Simulated Percentage Change Year-over-Year Actual Percentage Change Year-over-Year

Figure 6.3--Response to an 8\% Increase in the Widget Order Rate

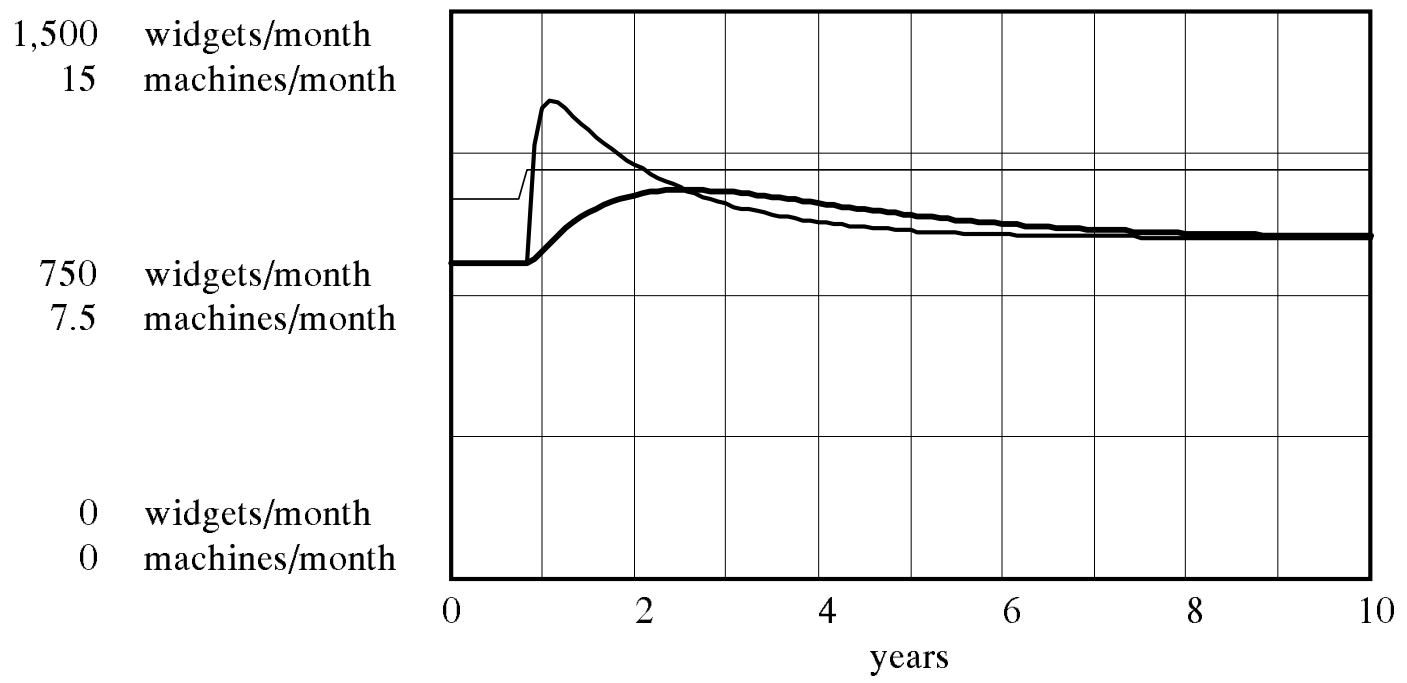

Widget Order Rate

widgets/month Machine Order Rate machines/month Machine Production Rate machines/month 
Figure 6.4--Response to an $8 \%$ Increase in the Widget Order Rate

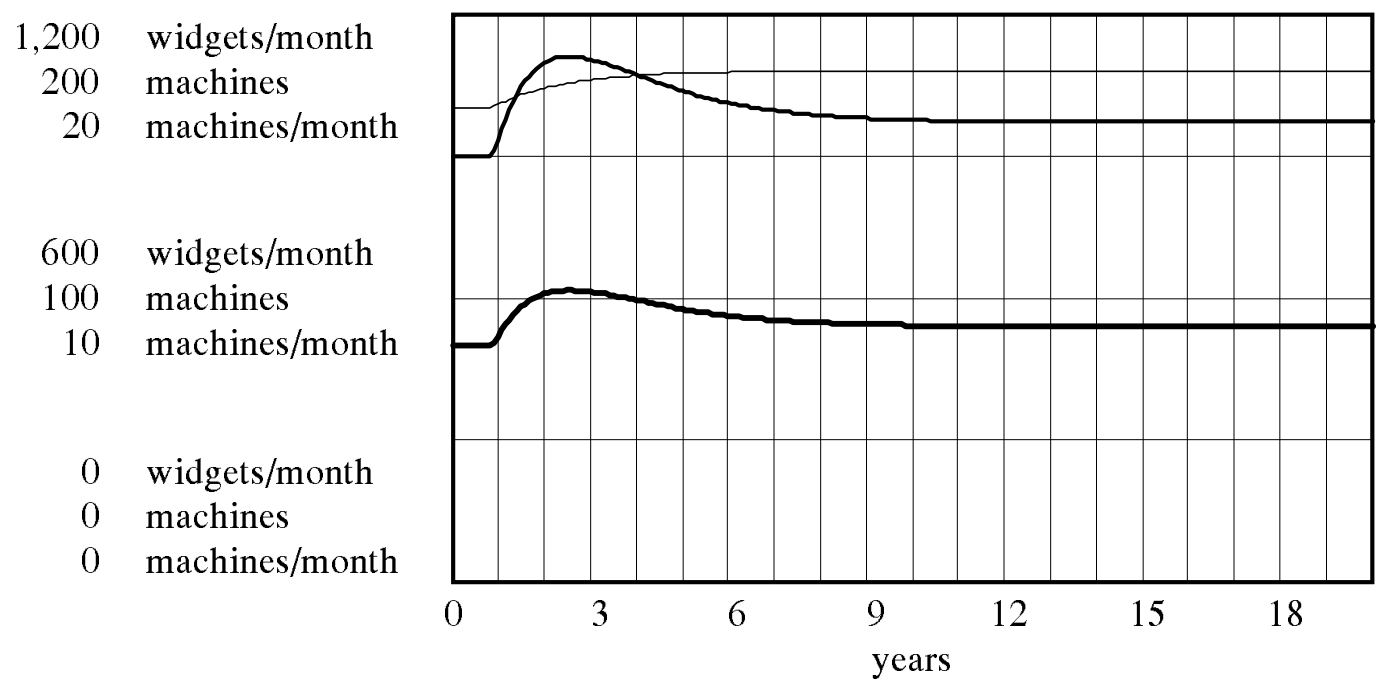

Forecasted Widget Demand — widgets/month Machine Backlog — machines Forecasted Machine Demand — machines/month

Figure 6.5--Employee Response to 8\% Increase in the Widget Order Rate

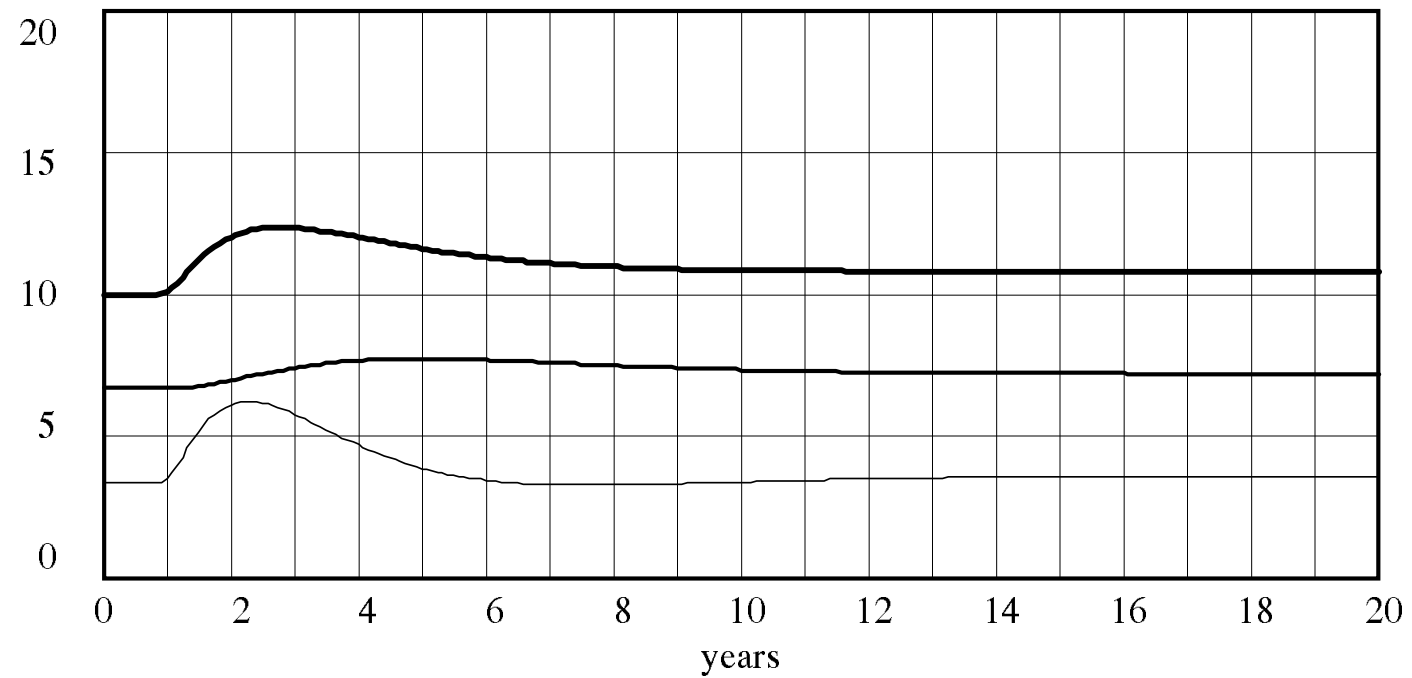

Rookie Employees employees

Trained Employees employees

Effective Employees (=Machine-Maker Capacity) employees 
Fig. 6.6--Beer-Game and Machine-Tool Effects from an 8\% Increase in WOR

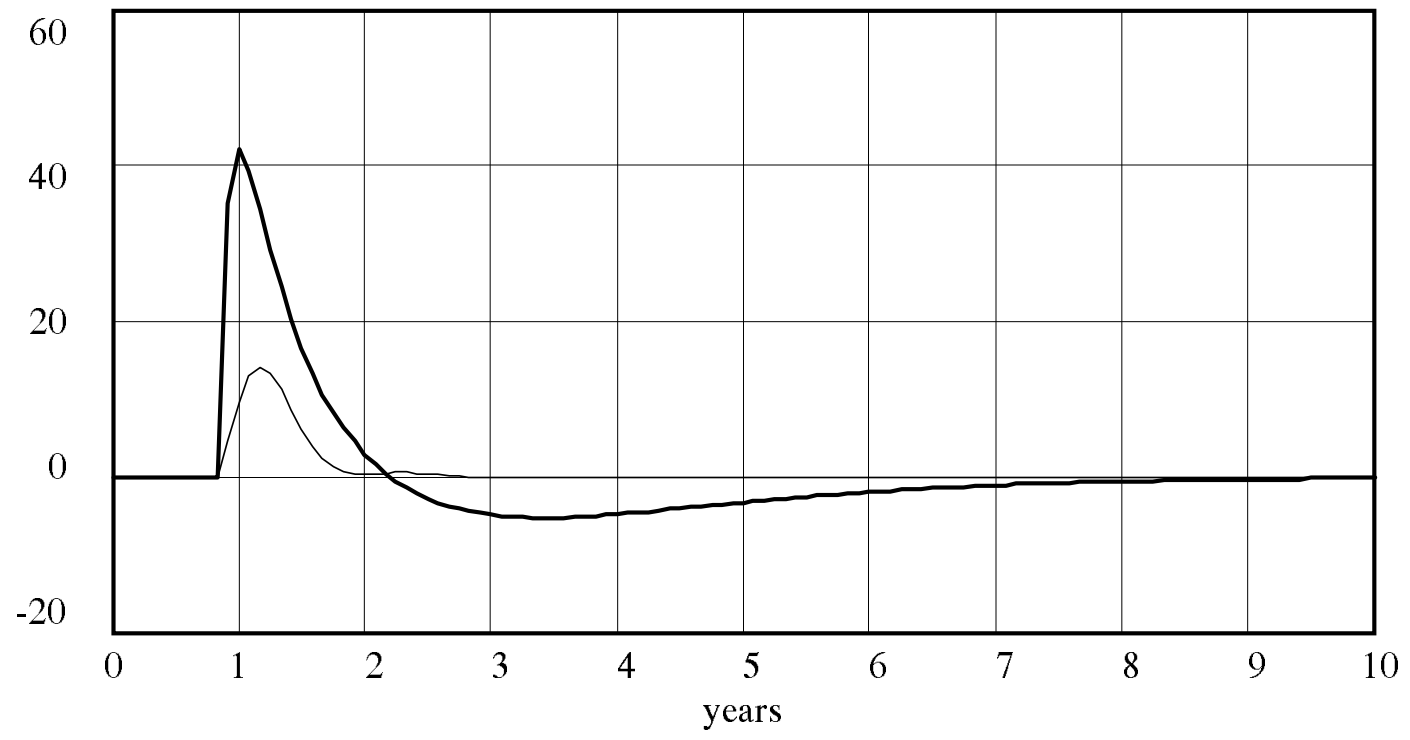

Change in Parts Orders (year-over-year) —— percentage Change in Machine Orders (year-over-year) — percentage

Figure 6.7--Machine Maker Capacity vs. Increasing Volatility

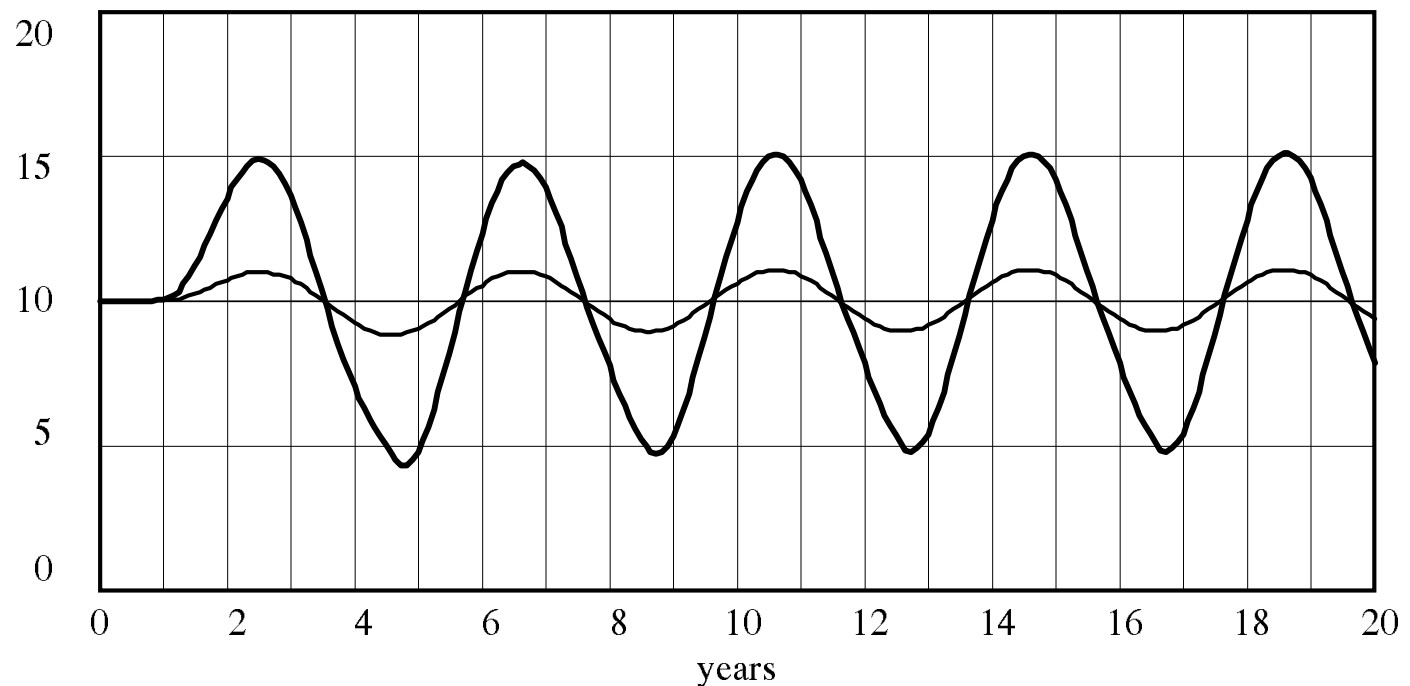

Equilibrium Input employees $8 \%$ Input employees $40 \%$ Input employees 
Figure 6.8--Input Widget Order Rate Series

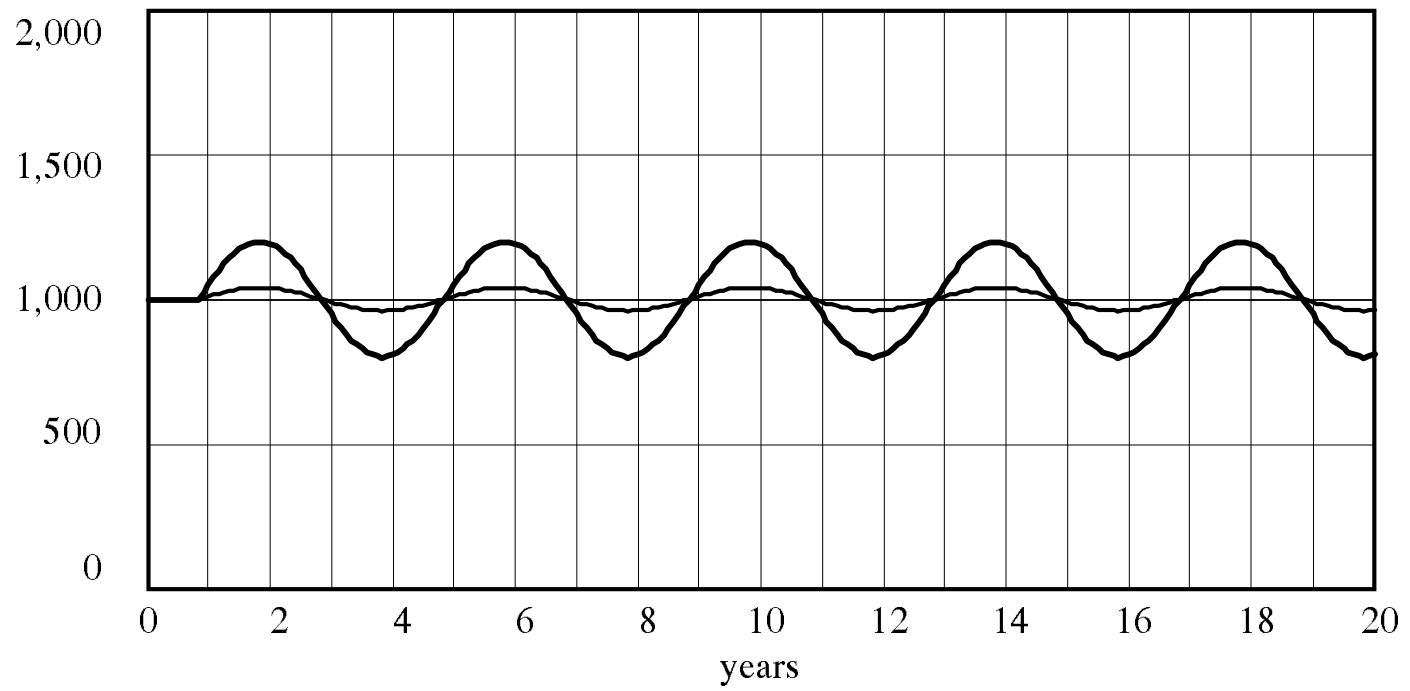

Equilibrium Input $8 \%$ Input widgets/month widgets/month $40 \%$ Input widgets/month

Figure 6.9--Machine Maker Total Employees vs. Increasing Volatility

40

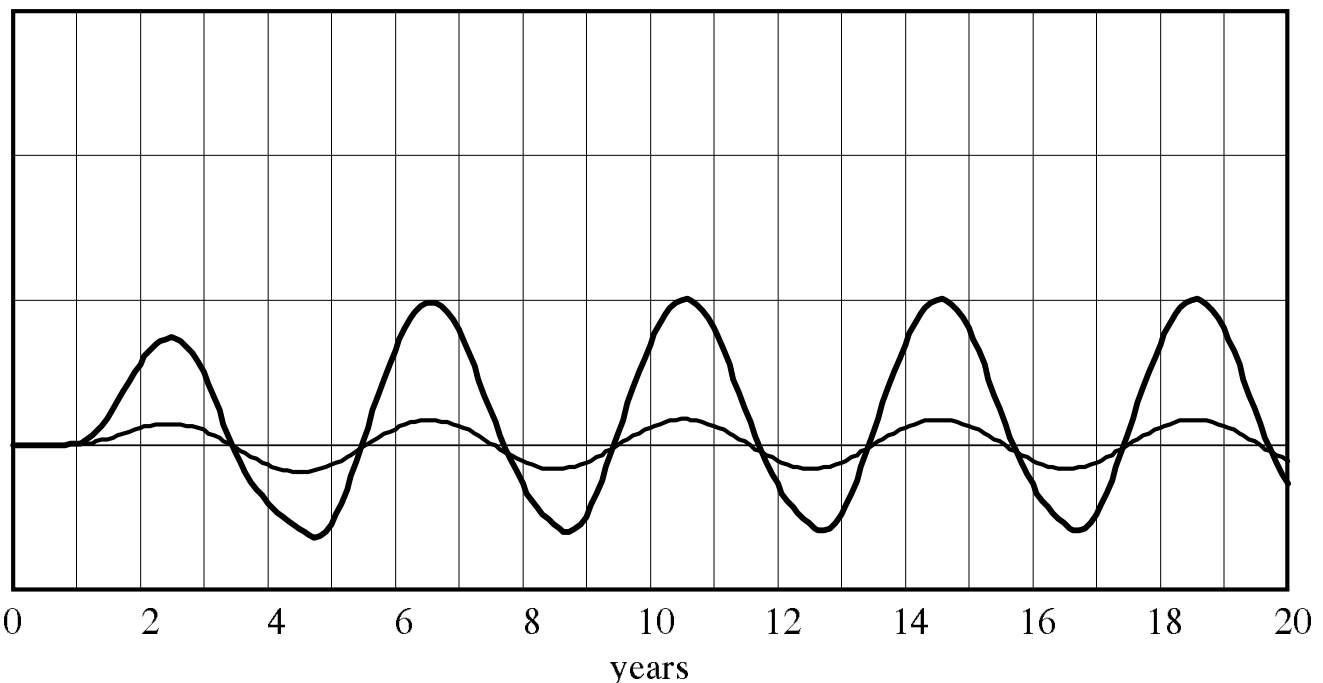

Equilibrium Input

$8 \%$ Input

employees

$40 \%$ Input

employees employees 
Fig. 6.10--Machine Maker Rookie Employee Percentage vs. Increasing Volatility

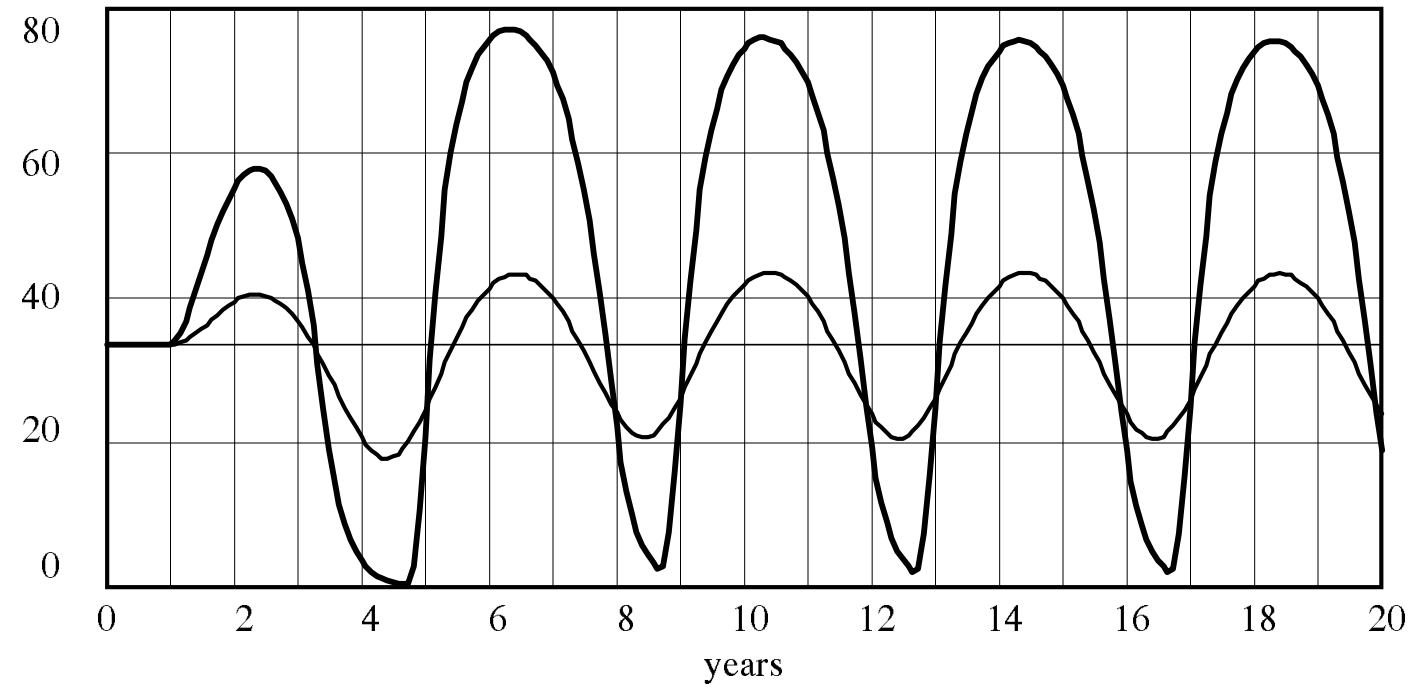

Equilibrium Input $8 \%$ Input $40 \%$ Input

percent percent percent

Figure 6.11--Experienced Employee Cutbacks vs. Increasing Volatility

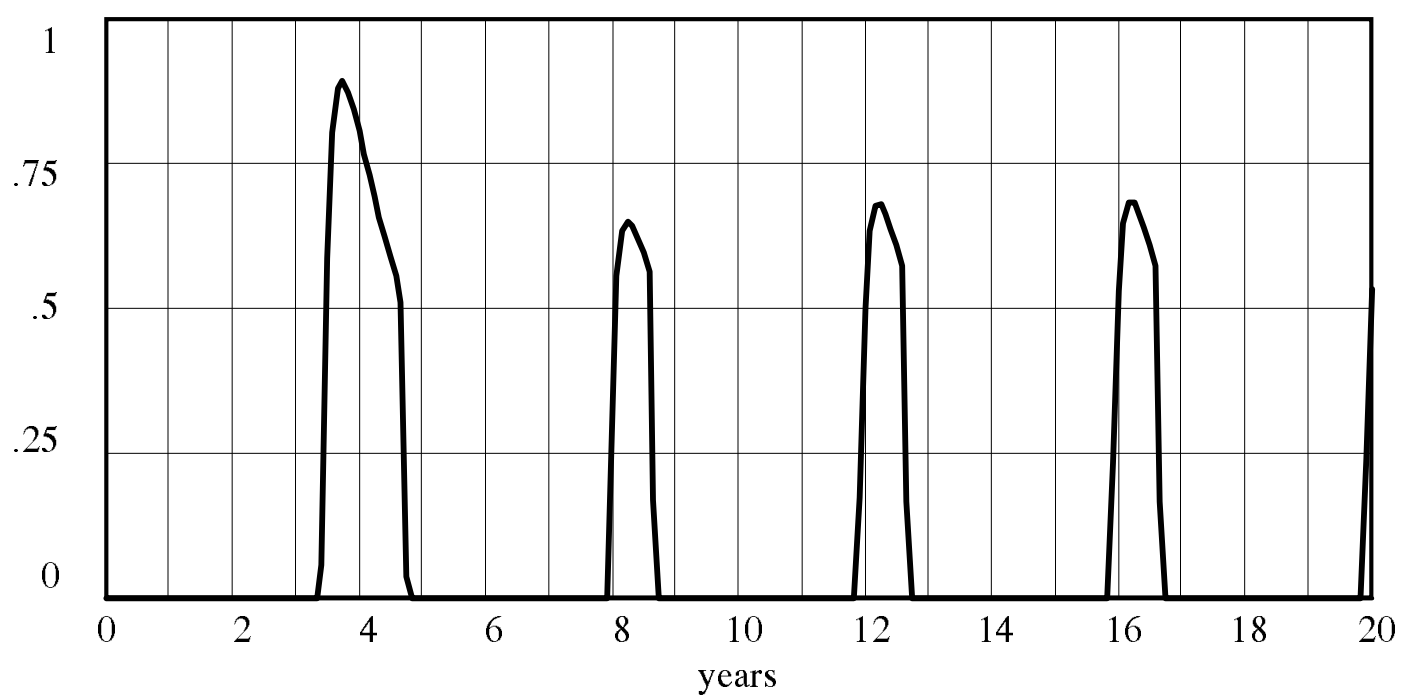

Equilibrium Input

$8 \%$ Input

employees

$40 \%$ Input

employees employees 
Figure 6.12--Response of Machine Backlog under 40\% Input to Stockpiling

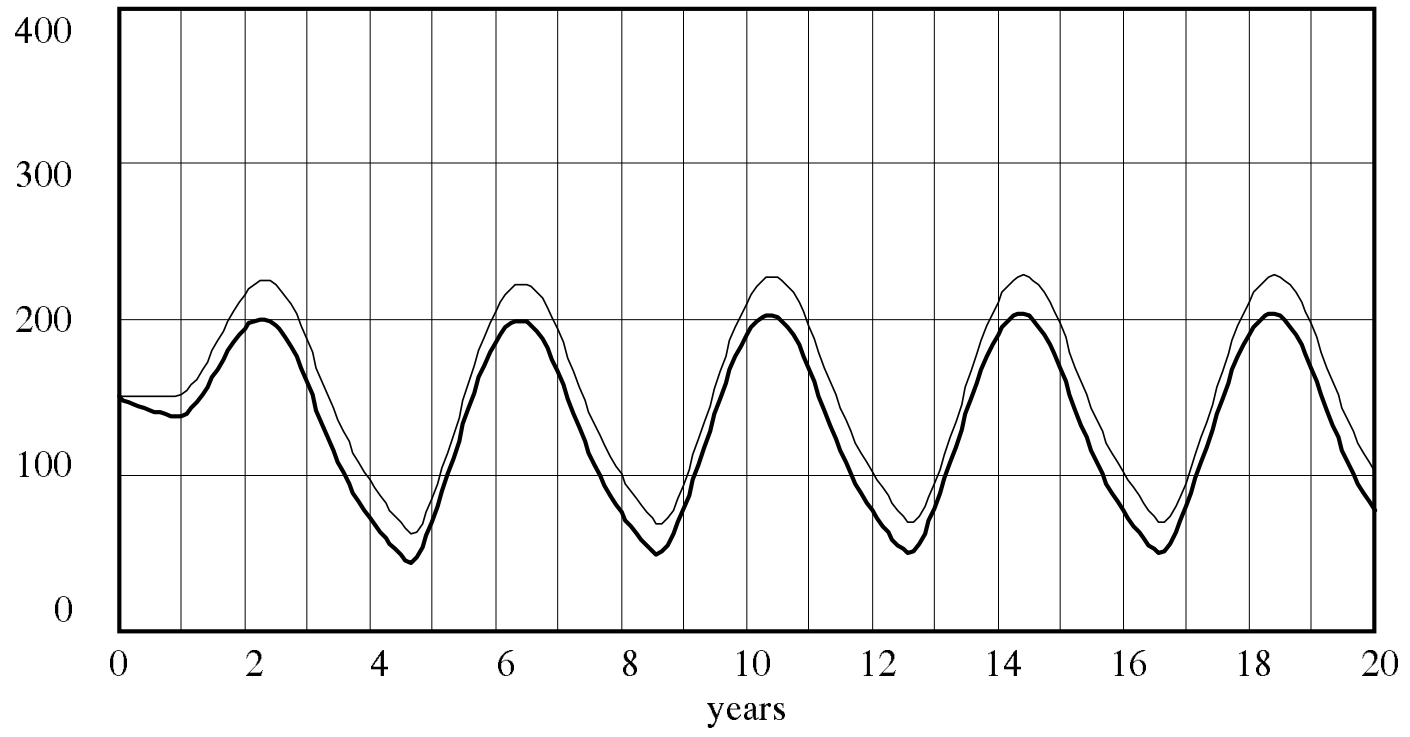

No Stockpiling

Increase IMPR by $20 \%$

machines machines

Fig. 6.13--Response of Machine Backlog under 8\% Input to Halving Leadtime

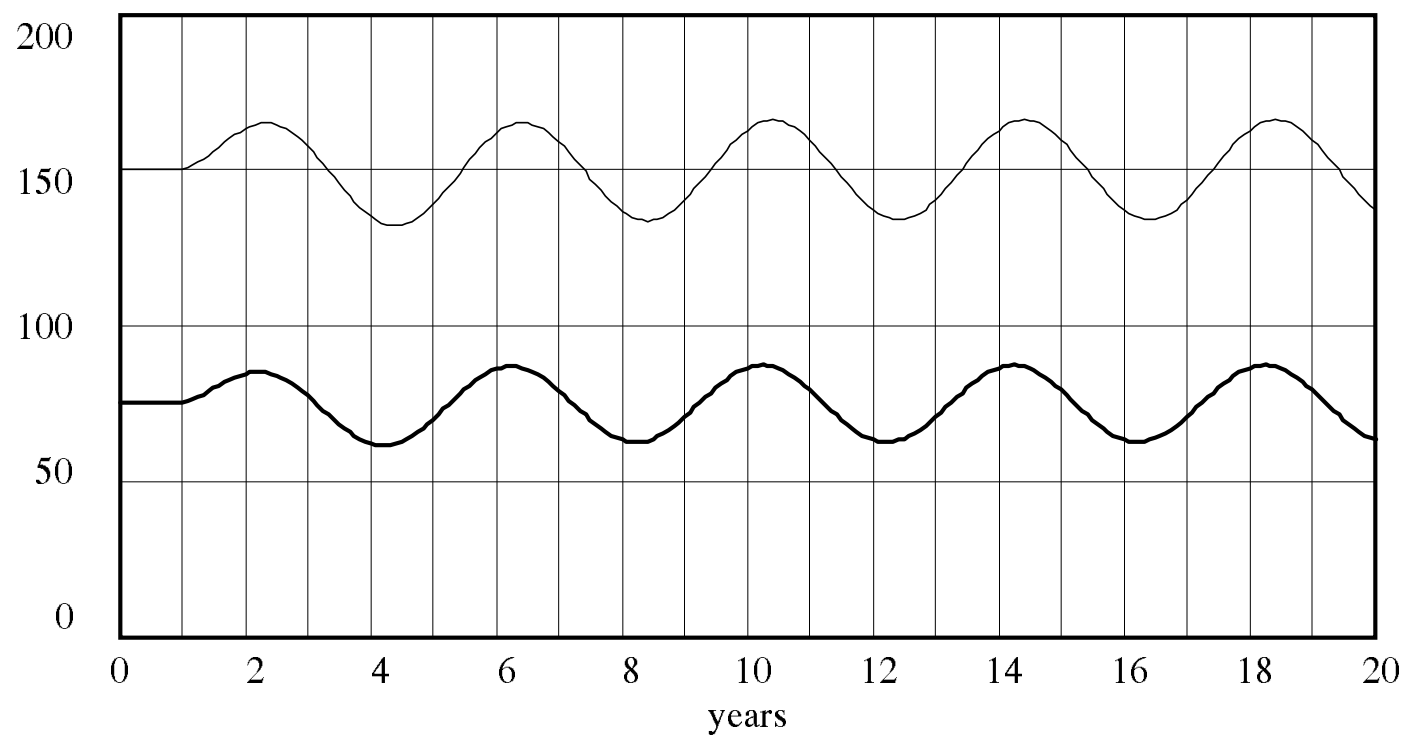

18 Month Machine Mfg. Leadtime (Base)

machines

9 Month Machine Mfg. Leadtime machines 
Figure 6.14--Response of Widget-Maker Capacity under 8\% Input

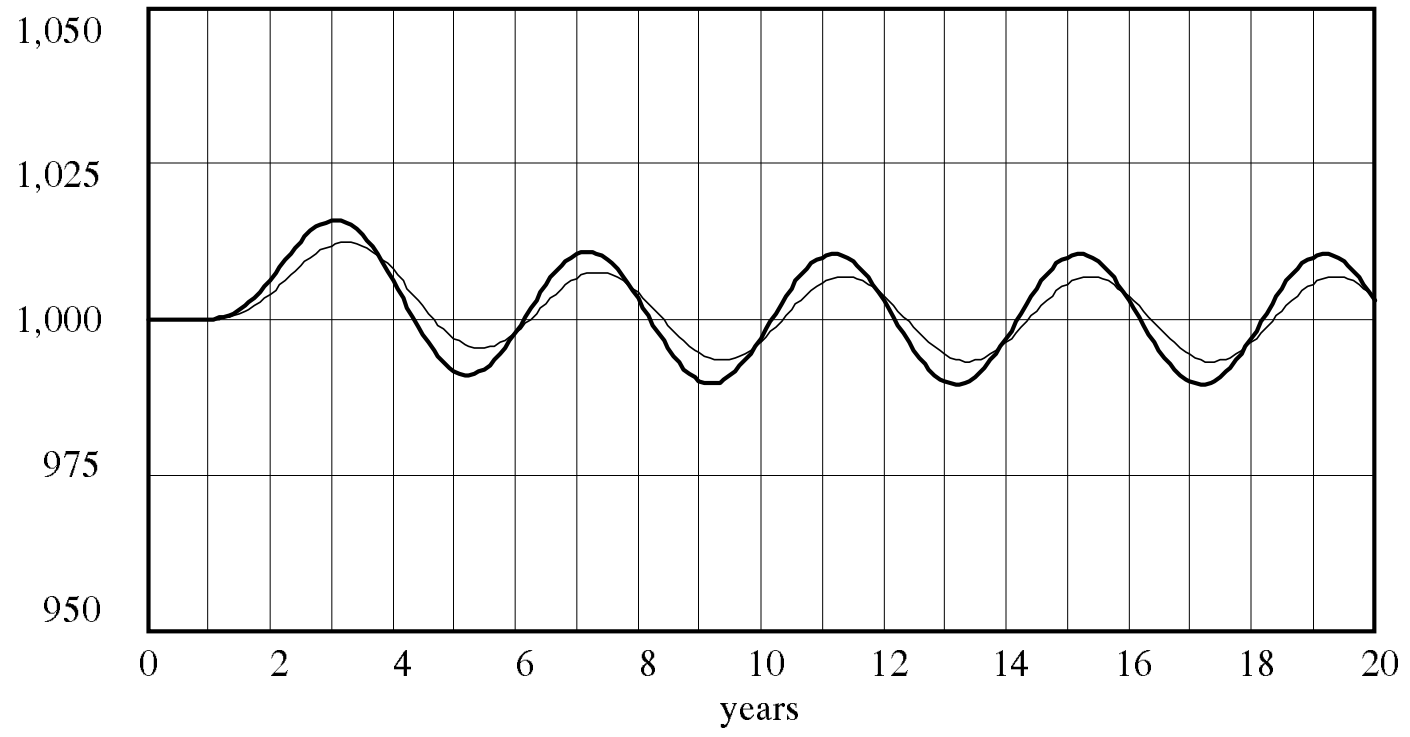

18 Month Machine Mfg. Leadtime (Base)

9 Month Machine Mfg. Leadtime

machines

machines

Figure 6.15--Response of Machine Order Rate to Policy Changes

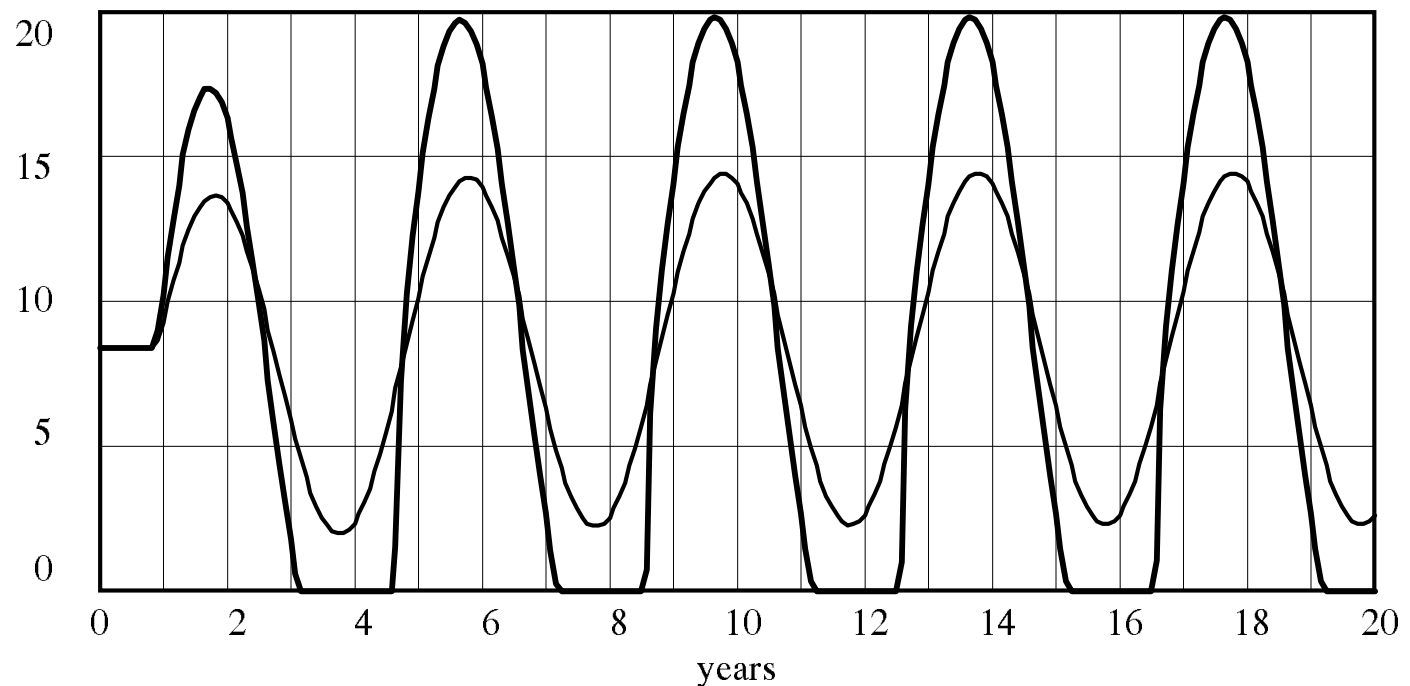

Base

Widget Forecast Horizon $=36$ months

machines/month

Machine Forecast Horizon $=36$ months

machines/month

machines/month 
Figure 6.16--Response of Machine Production Rate to Policy Changes

20

15

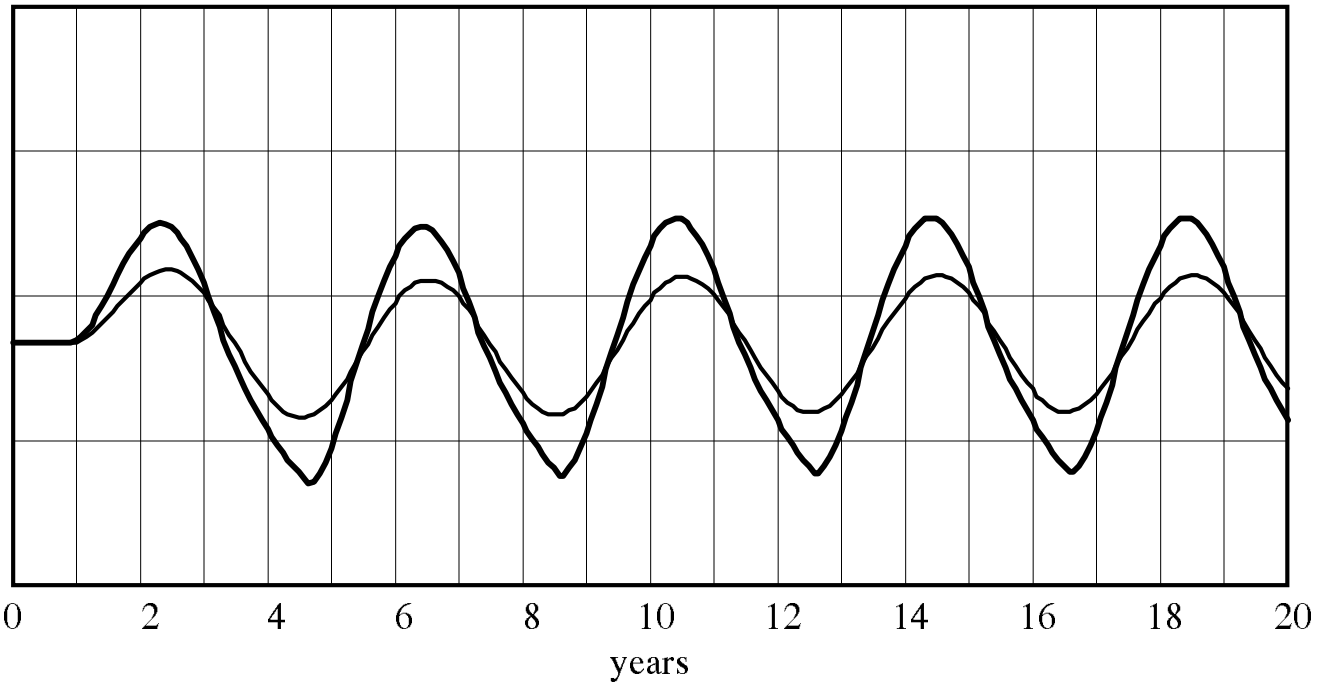

Base

Widget Forecast Horizon $=36$ months

Machine Forecast Horizon $=36$ months

machines/month

machines/month

machines/month

Figure 6.17--Response of Rookie Percentage to Policy Changes

80

60

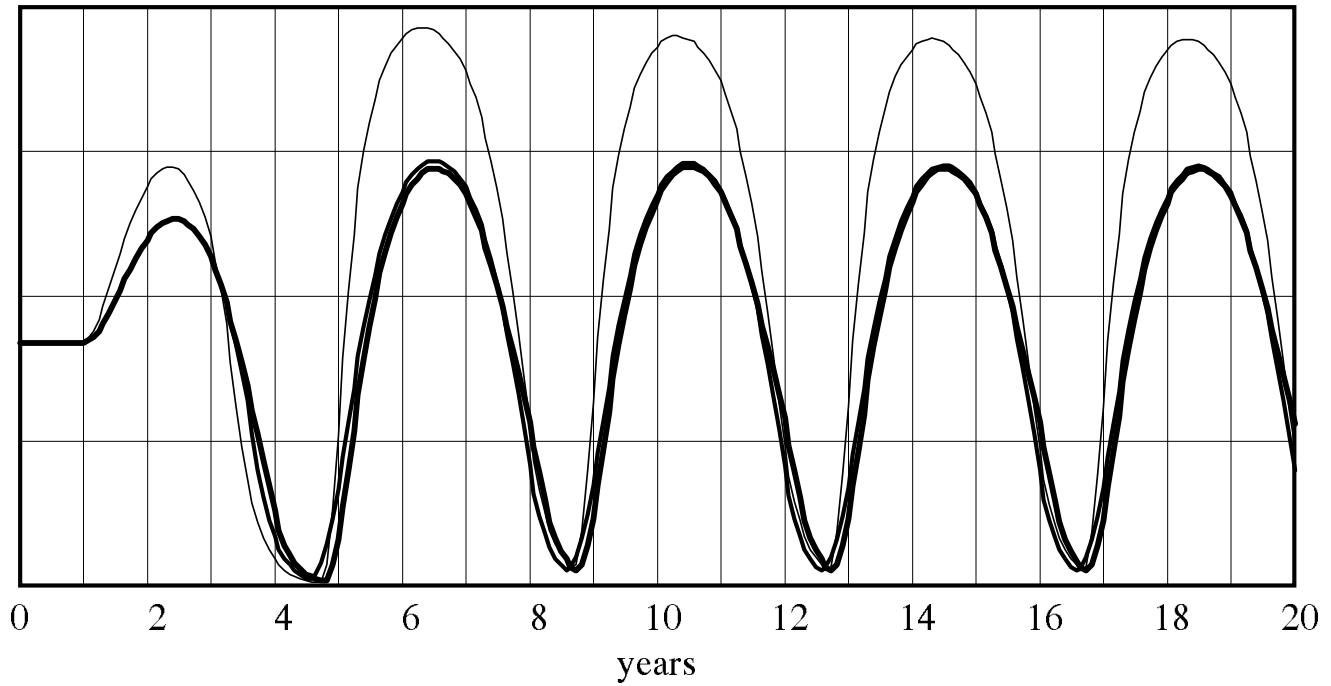

Base

Widget Forecast Horizon $=\mathbf{3 6}$ months

percentage

Machine Forecast Horizon $=36$ months

percentage

percentage 